This document is the accepted manuscript version of the following article:

Spuhler, D., Scheidegger, A., \& Maurer, M. (2018). Generation of sanitation system options for urban planning considering novel technologies. Water Research, 145, 259-278. https:// doi.org/10.1016/j.watres.2018.08.021.

This manuscript version is made available under the CC-BY-NC-ND 4.0

1icense http://creativecommons.org/1icenses/by-nc-nd/4.0/

\title{
Generation of sanitation system options for urban planning considering novel technologies
}

\author{
Spuhler \\ Dorothee \\ $1,2^{*}$ \\ Scheidegger \\ Andreas \\ 1, Maurer \\ $\operatorname{Max}$ \\ 1,2 \\ Eawag, Swiss Federal Institute of Aquatic Science and Technology, 8600 Dübendorf, Switzerland. \\ 1) Institute of Civil, Environmental and Geomatic Engineering, ETH Zürich, 8093 Zurich, Switzerland. \\ *) Corresponding author: Eawag, Swiss Federal Institute of Aquatic Science and Technology. Überlandstrasse 133, \\ 8600 Dübendorf, Switzerland. E-mail: dorothee.spuhler@eawag.ch
}

\section{Keywords:}

- Sustainable sanitation

- Strategic urban sanitation planning

- Sanitation systems

- $\quad$ Structured Decision Making (SDM)

- Alternative generation

\section{Abstract}

The identification of appropriate sanitation systems is particularly challenging in developing urban areas where local needs are not met by conventional solutions. While structured decision-making frameworks such as Community-Led Urban Environmental Sanitation (CLUES) can help facilitate this process, they require a set of sanitation system options as input. Given the large number of possible combinations of sanitation technologies, the generation of a good set of sanitation system options is far from trivial.

This paper presents a procedure for generating a set of locally appropriate sanitation system options, which can then be used in a structured decision-making process. The systematic and partly automated procedure was designed (i) to enhance the reproducibility of option generation; (ii) to consider all types of conventional and novel technologies; (iii) to provide a set of sanitation systems that is technologically diverse; and (iv) to formally account for uncertainties linked to technology specifications and local conditions.

We applied the procedure to an emerging small town in Nepal. We assessed the appropriateness of 40 technologies and generated 17,955 appropriate system options. These were classified into 16 system templates including on-site, urinediverting, biogas, and blackwater templates. From these, a subset of 36 most appropriate sanitation system options were selected, which included both conventional and novel options.

We performed a sensitivity analysis to evaluate the impact of different elements on the diversity and appropriateness of the set of selected sanitation system options. We found that the use of system templates is most important, followed by the use of a weighted multiplicative aggregation function to quantify local appropriateness. We also show that the optimal size of the set of selected sanitation system options is equal to or slightly greater than the number of system templates.

As novel technologies are developed and added to the already large portfolio of technology options, the procedure presented in this work may become an essential tool for generating and exploring appropriate sanitation system options. 


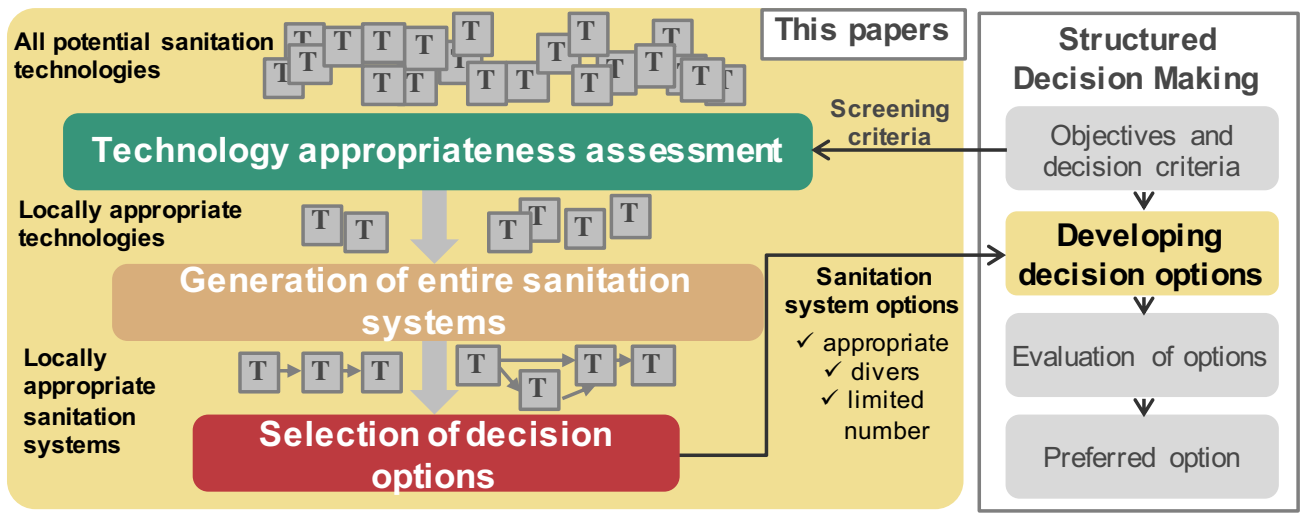

\section{Abbreviations/glossary:}

$\begin{array}{ll}\text { SDM } & \text { Structured decision making } \\ \text { MCDA } & \text { Multi-criteria decision analysis } \\ \text { CLUES } & \text { Community-Led Urban Environmental Sanitation } \\ \text { Tech } & \text { Technology option } \\ \text { AppCase } & \text { Application case } \\ \text { SanSys } & \text { Sanitation system } \\ \text { Product } & \text { Sanitation product } \\ \text { FG } & \text { Functional group. There exist five FGs: U: User interface; S: Collection and storage. C: Conveyance; T: } \\ & \text { Treatment; and D: Reuse or Disposal. Uadd is a variation of U } \\ \text { ST } & \text { System Template } \\ A S_{t, c} & \text { Appropriateness Score for criteria c and Tech t } \\ T A S & \text { Technology Appropriateness Score } \\ S A S & \text { System Appropriateness Score } \\ Q & \text { Set of selected SanSys } \\ \text { Nb } & \text { Number } \\ \text { SI } & \text { Supporting Information }\end{array}$

\section{Introduction}

\subsection{The global sanitation crisis}

Sanitation is crucial for human and environmental health as well as social and economic development (WHO 2013). Its critical role for development was recognized in the Millennium Development Goals (MDG, UN 2000) and was taken further in the Sustainable Development Goals (SDGs) for 2030 (UN 2015). Despite these efforts, the world has fallen short of its MDG sanitation target, leaving 2.3 billion people without access to basic sanitation facilities and even more (WHO and UNICEF 2017) without integration into a fully functioning sanitation system. The situation is particularly challenging in the urban areas of developing countries, where most current population growth is taking place (UNFPA 2007). These areas are characterized by high population densities, the low financial power of their citizens, and a predominantly informal sanitation sector (Dodman et al. 2013, Isunju et al. 2011, Ramôa et al.
2016, Tremolet et al. 2010). If sanitary facilities exist, they are often only basic systems such as pit latrines and septic tanks (Munamati et al. 2017). Systematic collection and safe disposal of wastewater and sludge are often missing (Strande 2014, WSP 2014), leading to $90 \%$ of urban wastewater globally being discharged without appropriate treatment (UNW-DPC 2013).

\subsection{Failure of conventional approaches}

The abandonment or breakdown of sanitation infrastructures in developing urban areas is a common phenomenon (Barnes and Ashbolt 2006), which indicates the failure of conventional approaches to sanitation planning and service provision (McConville 2010). Planning approaches have a tendency to be top-down, technology-driven, and focussed on implementations of technology or regional master plans. This has led to inappropriate technology choices for local physical and social environments and the often-limited available human and financial resources for maintenance and operation (Kalbermatten et al. 1980, Kvarnström et al. 2011, Menck 1973, Starkl et al. 2013, Tilley et al. 2014a). 


\subsection{Sustainable sanitation systems planning}

It is now widely accepted that sanitation planning should consider the entire sanitation chain and rely on the principles of sustainability. Sustainable sanitation systems not only protect and promote human health; they also protect the environment and natural resources and are economically viable, socially acceptable, and technically and institutionally appropriate (Kvarnström et al. 2004, SuSanA 2008). A sanitation system is a set of technologies which in combination treat and manage human waste and wastewater from the source of generation to the final point of reuse or disposal. This includes five functional groups (FGs): the user interface, collection and storage, conveyance, semi-centralized treatment, and reuse or disposal (Tilley et al. 2014b). Each technology should be appropriate to the contextspecific health, environmental, economic and financial, socio-demographic, and institutional conditions. This strongly highlights the multicriteria aspect of sanitation systems planning (Zurbrügg et al. 2009) and the importance of trade-offs and stakeholder preferences (e.g. Lennartsson et al. 2009, Motevallian and Tabesh 2011, Willetts et al. 2013).

\subsection{Available planning frameworks}

Several sanitation system planning frameworks have been proposed (e.g. Ashley et al. 2008, Bracken et al. 2005, Hendriksen et al. 2012, Kvarnström et al. 2011, Kvarnström and Petersens 2004, Lennartsson et al. 2009, Lundie et al. 2006, Lüthi et al. 2011, Nayono 2014, Parkinson et al. 2014, Tilley et al. 2010, van Buuren and Hendriksen 2010). Many of them use structured decision-making (SDM) in combination with multicriteria decision analysis (MCDA). SDM helps to structure the decision-making process and to deliver insights about what matters to diverse stakeholders and how well various objectives may be satisfied by different decision options (Gregory et al. 2012, Marttunen et al. 2017). Well-known SDM frameworks for sanitation planning in urban areas of developing countries include Community-Led Urban Environmental Sanitation, CLUES (Lüthi et al. 2011, Lüthi and Parkinson 2011, Sherpa et al. 2012), and Sanitation 21 (Parkinson et al. 2014).

\subsection{Lack of adequate decision options creation}

Planning and decision-making in developing urban settings still face various practical challenges (Barnes and Ashbolt 2006, McConville 2010, Ramôa et al. 2018). Amongst these, the systematic generation of decision options is one of the more substantial weaknesses (Hajkowicz and Collins 2007). In particular, the diversity of available technologies, the multiple sustainability dimensions, and their corresponding criteria are often not sufficiently considered.

Approaches to option generation that have been applied to sanitation include cause-effect analysis, creativitybased techniques such as brainstorming, and mixed approaches such as decision matrices and strategy tables (Eisenführ et al. 2010, Gregory et al. 2012, Keeney 1996, Larsen et al. 2010, McConville et al. 2014, Tilley et al. $2014 b)$. The results of these procedures rely strongly on the available expertise and are therefore somewhat arbitrary.

To overcome this disadvantage, the Compendium of Sanitation Systems and Technologies (Tilley et al. 2014b) presents a compilation of available technologies and thus enables the systematic creation of sanitation system options by combining compatible technologies. The disadvantage of this approach is that it results in several hundred thousand potential options for sanitation systems.

Option generation is complicated by the emergence of many novel technologies in the recent years, especially for on-site sanitation and semi-centralized systems (e.g. Amoah et al. 2016, Larsen et al. 2016, Parker 2014, Tilmans et al. 2015, Tobias et al. 2017). While novel technologies increase engineering flexibility and allow resource recovery, they also substantially increase the complexity of creating decision options.

Decision-making processes require a manageable number of options. In reality, it is often hard to consider more than several dozen decision options in an SDM process (e.g. with multiple-attribute value theory, MAVT, or multiple-attribute utility theory, MAUT) or six to eight according to (Gregory et al. 2012, chap. 7). Common methods to decrease the option space are Pareto optimality or dominance (e.g. Chen et al. 2008), sequential screening in combination with subset selection (Kilgour et al. 2004), and screening by restriction and aspiration levels (Eisenführ et al. 2010). The problem with these methods is that they require information on both the preferences of the stakeholders and the performance of options. However, this information is typically unavailable at the structuring phase of decisionmaking. Moreover, screening carries the risks that good options are discarded and that the criteria used imply value trade-offs (Gregory et al. 2012, Keeney 2002). Therefore, screening procedures need to carefully consider uncertainties and use criteria that can be exogenously defined and are independent of stakeholders (Eisenführ et al. 2010, Gregory et al. 2012).

\subsection{Aim of this paper}

The aim of this methodological paper is to present and exemplify a systematic procedure designed to generate a set of sanitation system options that can be used in a structured decision-making process (Figure 1). The procedure is able to 
- $\quad$ systematically include all types of conventional and novel technologies for building entire sanitation systems;

- $\quad$ provide a limited set of sanitation system options that (i) are appropriate to a given application case and (ii) incorporate diverse technologies and system configurations; and

- consider the uncertainties relating to the technology properties and local conditions.

The procedure only generates technical options and does not include financing or maintenance schemes. It is targeted at planners and engineers and intended as support for the structuring phase of a decision-making process, as Figure 1 explains.

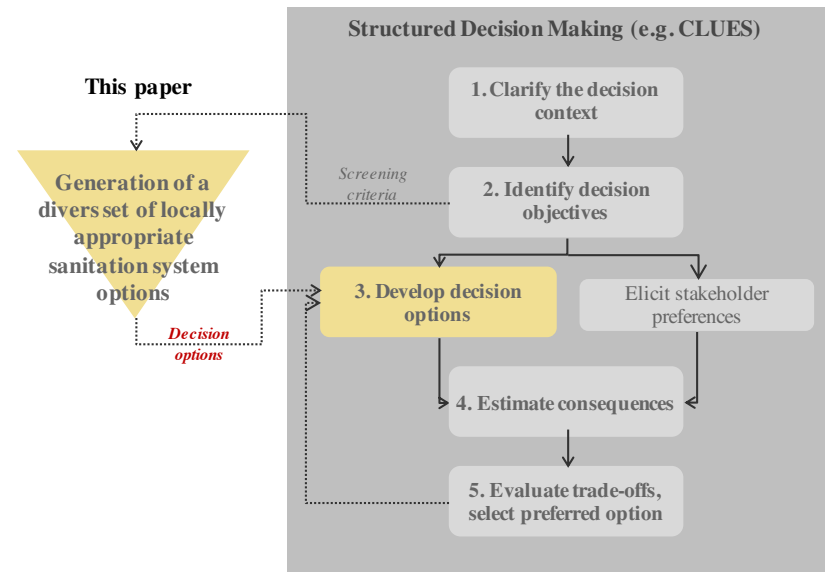

Figure 1: Schematic illustration of the wider structured decision making (SDM) framework in which the procedure presented here is integrated. The procedure is intended to generate a limited and diverse set of locally appropriate sanitation system options as an input into the SDM process and is targeted at planners and engineers. The schematic of the SDM process was adapted from (Schuwirth et al. 2012) and (Lüthi et al. 2011).

\section{Model development and methods}

\subsection{Overview of the procedure}

The procedure is designed to generate a set of decision options as an input into the SDM process. Decision options, also called decision alternatives, are possible actions designed to address the decision objectives. Decision objectives describe a goal that should be achieved with one of the decision options. In other words, decision objectives describe what matters to the decisionmakers and stakeholders (Gregory et al. 2012). In this paper, we use the definition of sustainable sanitation as a proxy for typical urban sanitation planning decision objectives (Kvarnström et al. 2004, SuSanA 2008). The final decision entails the selection of a single decision option from a given set of decision options. In sanitation planning, a decision option generally consists of a sanitation system (see below) complemented by other aspects. In this paper, the term decision option always refers only to the technical part of a sanitation system. The procedure consists of three major steps; see Figure 2.

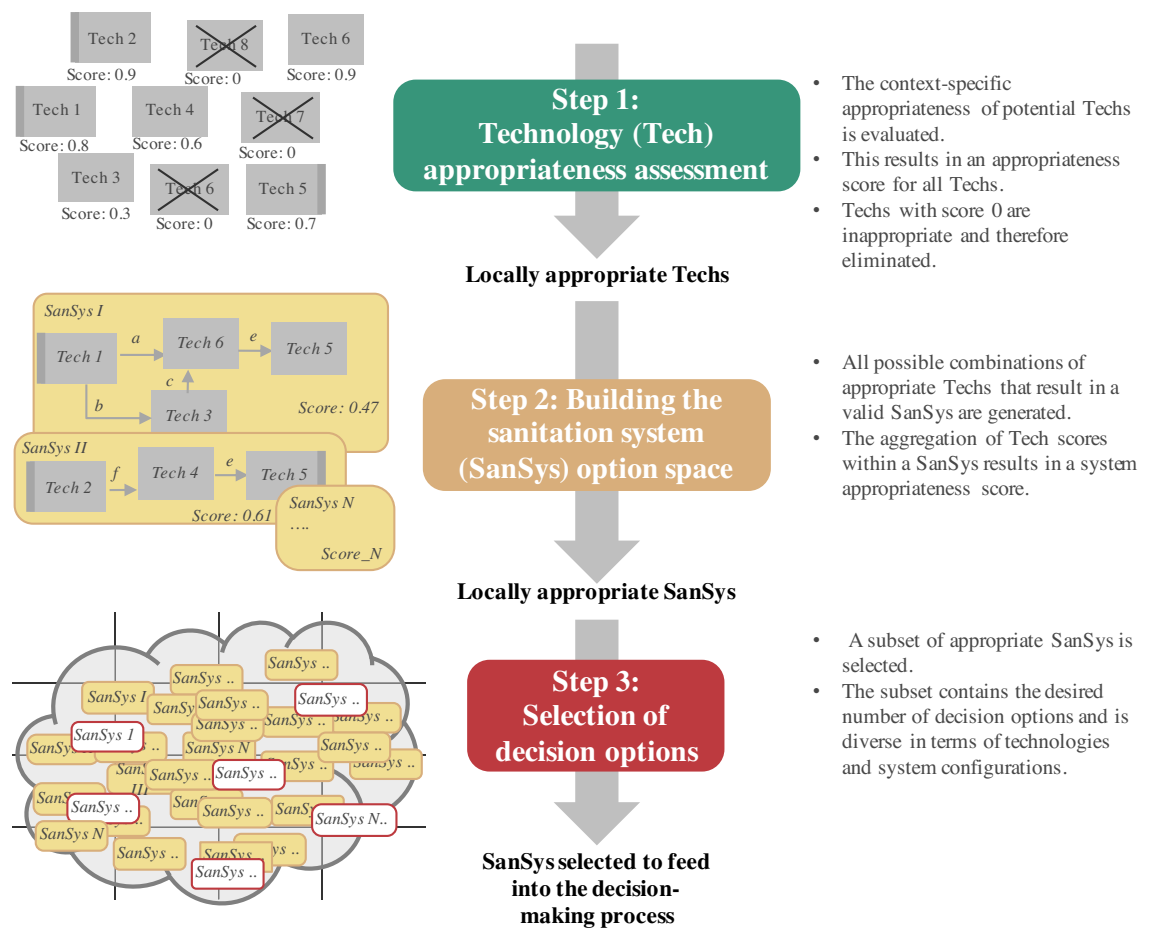

Figure 2: Detailed overview of the presented procedure. The procedure consists of three steps. In step one, the context-specific appropriateness of a set of potential technologies (Techs) is evaluated. In step two, all possible sanitation system (SanSys) options are generated by the combination of compatible Techs. In step 3, a subset of most appropriate and most diverse SanSys is selected to be used in the structured decision making (SDM) process. 


\subsection{Step 1: Appropriateness assessment of Techs}

The goal of this first step is to identify those technologies among all potential ones that are appropriate for a specific application case. A technology (Tech) is defined as any process, infrastructure, method or service that is designed to contain, transform or transport sanitation products (Maurer et al. 2012, Tilley et al. 2014b). The application case (AppCase) is the case study or context in which the presented procedure is applied. For example, if a Tech requires a water supply, and the provision of water is not possible in the AppCase, this Tech can be excluded immediately.

Most Techs can have multiple input and output products in different configurations. Sanitation products are materials that are generated either directly by humans (e.g. urine, faeces, greywater), the urban environment (e.g. stormwater), or by the Techs (e.g. sludge, blackwater, biogas). We use a standardised set of products based on the definition of Tilley et al. (2014b) (see also Figure 6). For instance, a septic tank can have blackwater and greywater as an input, or blackwater alone.

\subsubsection{Identification of screening criteria}

The appropriateness of Techs is evaluated on the basis of screening criteria derived from the overall decision objectives for sustainable sanitation as defined by (SuSanA 2008). Based on this definition, a sustainable sanitation system not only has to protect and promote human health by providing a clean environment and breaking the cycle of disease but also has to be economically viable, socially and institutionally acceptable, technically appropriate, and protective of the environment and natural resources. We translated this definition into five main decision objectives: (1) protection of human health, (2) financial and economic viability, (3) social and institutional acceptance, (4) technical functionality, and (5) protection of the environment and natural resources. We then established an overall objective bierarchy for sustainable sanitation planning: we compiled the lower level objectives for each of the five main decision objectives and listed the corresponding quantitative and qualitative attributes based on existing literature (e.g. Balkema et al. 2002, Chen and Beck 1997, Dunmade 2002, Krebs and Larsen 1997, Kvarnström et al. 2004, Larsen and Gujer 1997, Lennartsson et al. 2009, Lundin et al. 1999, Palme et al. 2005, Sahely et al. 2005). Attributes measure how well an option performs with respect to a decision objective. Other terms used for attributes are 'performance measures' and 'objective variables/functions' (Eisenführ et al. 2010). A summary of the literature review, the objective hierarchy, and the corresponding attributes are available in SI-A.

We then compiled a master list of screening criteria (see Table 1) by identifying decision objectives and corresponding attributes that fulfil three requirements: (i) they can be defined exogenously (they are 'fixed'); (ii) they do not involve trade-offs that might be weighted differently by different stakeholders; and (iii) they can be evaluated on the basis of the information and data generally available in the structuring phase of decisionmaking (i.e. baseline reports, local and regional statistics). The set of screening criteria contained in the master list overlap with the concept of appropriate technology (see Figure 3), which is a sub-domain of sustainable sanitation that evolved earlier (Bouabid and Louis 2015, Goldhoff 1976, Iwugo 1979, Kalbermatten et al. 1980, Loetscher 1999, Magara et al. 1986, Menck 1973, Schumacher 1973, Singhirunnusorn and Stenstrom 2009). The master list of screening criteria should be adapted to the local preferences in an AppCase. This contextualization is also important, as the requirements used for the identification of screening criteria can vary in different contexts. For instance, legal aspects are generally recognized as fixed (defined exogenously) in Switzerland but are seen as flexible in Nepal. Another example is that of financial criteria: in some cases, they are perceived as stakeholderindependent killer criteria, even though they involve major trade-offs.

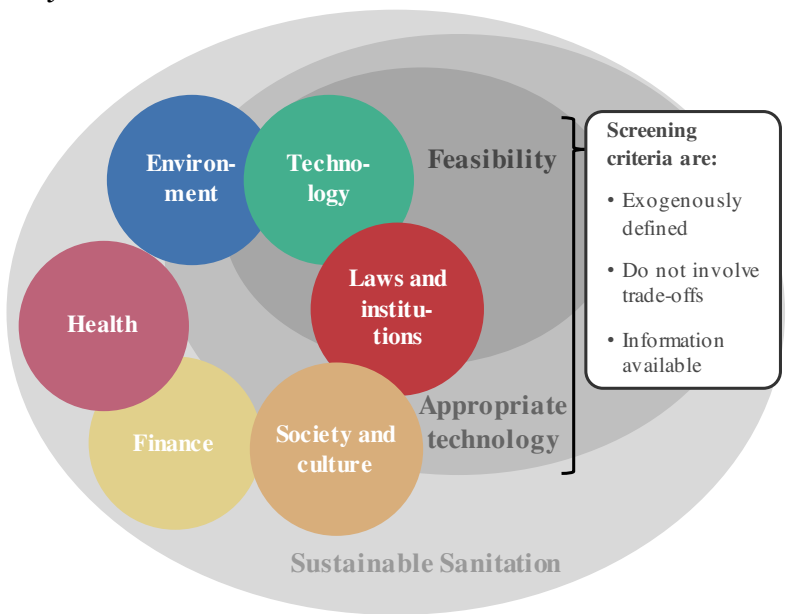

Figure 3: Dimensions of sustainable sanitation and overlap with other commonly defined concepts used to evaluate sanitation infrastructures. Screening criteria were derived from all sustainable sanitation criteria based on three factors:(i) they can be defined exogenously (ii) they do not involve trade-offs; and (iii) they can be evaluated on the basis of the information and data generally available at the structuring phase of decision making (i.e. baseline reports, local or regional statistics). The identified set of screening criteria overlaps with the concept of appropriate technology, which is a sub-domain of sustainable sanitation. 
Table 1: Master list of screening criteria used to assess the local appropriateness of technologies (Techs). To improve readability, we grouped the criteria into legal, technical, physical, demographic, socio-cultural, capacity and managerial, and financial aspects. Each screening criterion is further specified by an attribute for the Tech and one for the AppCase (see also Figure 4). Possible metrics for the evaluation of the attributes are also given. By matching the Tech attribute to the AppCase attribute, the appropriateness score for the given criterion can be evaluated. $(\mathrm{Nb}=$ number $)$.

\begin{tabular}{|c|c|c|c|c|}
\hline Nb & Screening criteria & Tech attribute & Possible evaluation metrics & AppCase attribute \\
\hline \multicolumn{5}{|c|}{ Legal } \\
\hline 1. & Effluent & Effluent quality & $\begin{array}{l}\text { Microbial quality (faecal coliforms, } \\
\text { helminths, viruses) } \\
\text { Chemical quality (toxic substances, } \\
\text { Nitrogen, Phosphorus, total solids, } \\
\text { biological oxygen demand, chemical } \\
\text { oxygen demand) }\end{array}$ & $\begin{array}{l}\text { Legal requirement for the } \\
\text { effluent }\end{array}$ \\
\hline 2. & Solid residue & Solid residue quality & $\begin{array}{l}\text { Microbial quality (faecal coliforms, } \\
\text { helminths, viruses) } \\
\text { Chemical quality (toxic substances, } \\
\text { Nitrogen, Phosphorus, total solids, } \\
\text { biological oxygen demand, chemical } \\
\text { oxygen demand) }\end{array}$ & $\begin{array}{l}\text { Legal requirement for the solid } \\
\text { residues }\end{array}$ \\
\hline \multicolumn{5}{|c|}{ Technical } \\
\hline 3. & Water & Water requirements & Litre per capita per year & Water availability \\
\hline 4. & Energy & Energy requirements & Kilowatt-hours per capita per year & Energy availability \\
\hline 5. & Water stability & $\begin{array}{l}\text { Vulnerability to water supply } \\
\text { disruption }\end{array}$ & Hours per day & $\begin{array}{l}\text { Frequency of water supply } \\
\text { disruption }\end{array}$ \\
\hline 6. & Energy stability & $\begin{array}{l}\text { Vulnerability to energy } \\
\text { supply disruption }\end{array}$ & Hours per day & $\begin{array}{l}\text { Frequency of energy supply } \\
\text { disruption }\end{array}$ \\
\hline 7. & Construction material & $\begin{array}{l}\text { Construction material } \\
\text { requirements }\end{array}$ & Pipes, pumps, concrete & $\begin{array}{l}\text { Construction material } \\
\text { available }\end{array}$ \\
\hline 8. & Spare parts & Spare parts requirements & Ladder & Spare parts supply \\
\hline 9. & Chemicals & Chemicals requirements & Ladder & Chemicals supply \\
\hline 10. & $\begin{array}{l}\text { Operation and } \\
\text { maintenance (O\&M) }\end{array}$ & $\begin{array}{l}\text { Frequency of } \mathrm{O \& M} \\
\text { requirements }\end{array}$ & Hours or event per capita per year & O\&M capacity \\
\hline \multicolumn{5}{|c|}{ Physical } \\
\hline 11. & Climate & Climate type requirements & Category: tropical, dry, temperate, cold & Type of climate \\
\hline 12. & Temperature & Temperature requirements & Celsius & Temperature range \\
\hline
\end{tabular}




\begin{tabular}{|c|c|c|c|c|}
\hline 13. & Flooding & Flooding tolerance & $\begin{array}{l}\text { Days of flooding per year accepted } \\
\text { (scale to be defined) }\end{array}$ & Flooding occurrence \\
\hline 14. & Area & Plot area requirements & Meter square per person & $\begin{array}{l}\text { Average free area available per } \\
\text { person }\end{array}$ \\
\hline 15. & Vehicle access & Access requirements & $\begin{array}{l}\text { Per cent ( } \mathrm{m}^{2} \text { of buildings } / \mathrm{m}^{2} \text { of total } \\
\text { area) }\end{array}$ & Accessibility of households \\
\hline 16. & Slope & Slope requirements & Per cent & Slope distribution \\
\hline 17. & Soil type & $\begin{array}{l}\text { Soil type / soil permeability } \\
\text { range tolerated }\end{array}$ & $\mathrm{cm} /$ hours & Soil type occurrence \\
\hline 18. & Groundwater depth & $\begin{array}{l}\text { Groundwater depth } \\
\text { requirements }\end{array}$ & Meter & Groundwater depth occurrence \\
\hline 19. & Excavation & Excavation requirements & Constructed scale & Ease of excavation \\
\hline \multicolumn{5}{|c|}{ Demographic } \\
\hline 20. & Population & $\begin{array}{l}\text { Size of population that can be } \\
\text { served }\end{array}$ & $\begin{array}{l}\text { Number of capita per household or } \\
\text { volume of flow stream }\end{array}$ & Service capacity requirements \\
\hline 21. & Population density & $\begin{array}{l}\text { Range of population density } \\
\text { tolerated }\end{array}$ & Capita per kilometre square & Current population density \\
\hline 22. & Volume stability & $\begin{array}{l}\text { Potential to accommodate } \\
\text { changing water volumes }\end{array}$ & Litre per capita per day & $\begin{array}{l}\text { Expected wastewater flows at } \\
\text { the end of project design life }\end{array}$ \\
\hline 23. & Pollution stability & $\begin{array}{l}\text { Potential to accommodate } \\
\text { higher pollution loads }\end{array}$ & $\begin{array}{l}\text { Milligram of biological oxygen } \\
\text { demand per capita and day }\end{array}$ & $\begin{array}{l}\text { Expected BOD5 load at the } \\
\text { end of project design life }\end{array}$ \\
\hline \multicolumn{5}{|c|}{ Socio-cultural } \\
\hline 24. & Religious constraints & $\begin{array}{l}\text { Compatibility with religious } \\
\text { constraints }\end{array}$ & Ladder or range & Socio-cultural requirements \\
\hline 25. & Cultural constraints & $\begin{array}{l}\text { Compatibility with cultural } \\
\text { constraints }\end{array}$ & Ladder or range & Cultural requirements \\
\hline 26. & User awareness & User awareness requirements & Ladder & Range, to be defined \\
\hline \multicolumn{5}{|c|}{ Capacity and managerial } \\
\hline 27. & Construction skills & $\begin{array}{l}\text { Construction skills } \\
\text { requirements }\end{array}$ & $\begin{array}{l}\text { Ladder, e.g. from } 0 \text { to } 4 \text { : none, mason, } \\
\text { specially trained mason, } \\
\text { implementation engineer, supervisor }\end{array}$ & Construction skills availability \\
\hline 28. & Design skills & Design skills requirements & $\begin{array}{l}\text { Ladder, e.g. from } 0 \text { to } 5 \text { : none, } \\
\text { unskilled labour, mason, specially }\end{array}$ & Design skills availability \\
\hline
\end{tabular}




\begin{tabular}{|c|c|c|c|c|}
\hline & & & $\begin{array}{l}\text { trained mason, planning engineer, } \\
\text { supervisor }\end{array}$ & \\
\hline 29. & Management & Required management level & $\begin{array}{l}\text { Low, medium, high } \\
\text { household, shared, city }\end{array}$ & Preferred management level \\
\hline \multicolumn{5}{|c|}{ Financial } \\
\hline 30. & Investment costs & $\begin{array}{l}\text { Investment costs } \\
\text { requirements }\end{array}$ & Dollar per person & Available investment capital \\
\hline 31. & Annual costs & Annual costs requirements & $\begin{array}{l}\text { Capital expenditures and operational } \\
\text { expenditure in dollar per person per } \\
\text { year }\end{array}$ & Available funds for operation \\
\hline
\end{tabular}

\subsubsection{Evaluation of screening criteria and attributes}

The evaluation of screening criteria is also highly contextdependent (Hoffmann et al. 2000). Therefore, each screening criterion consists of a pair of Tech and AppCase attributes, which characterize the Tech and the AppCase respectively (see Figure 4). To account for uncertainties, we use probability functions to parametrize the attributes. Each pair of Tech and AppCase attributes consists of one probability density or distribution function (e.g. the water availability for a given AppCase, $\mathrm{p}$ (water availability)) and one conditional probability (e.g. the performance of a Tech given a certain water availability $P($ performance $\mid$ water availability)), varying between 0 and 100\%. Whether the density or the conditional probability is used for the AppCase or the Tech is not important as long as both types of functions are always represented for one criterion.

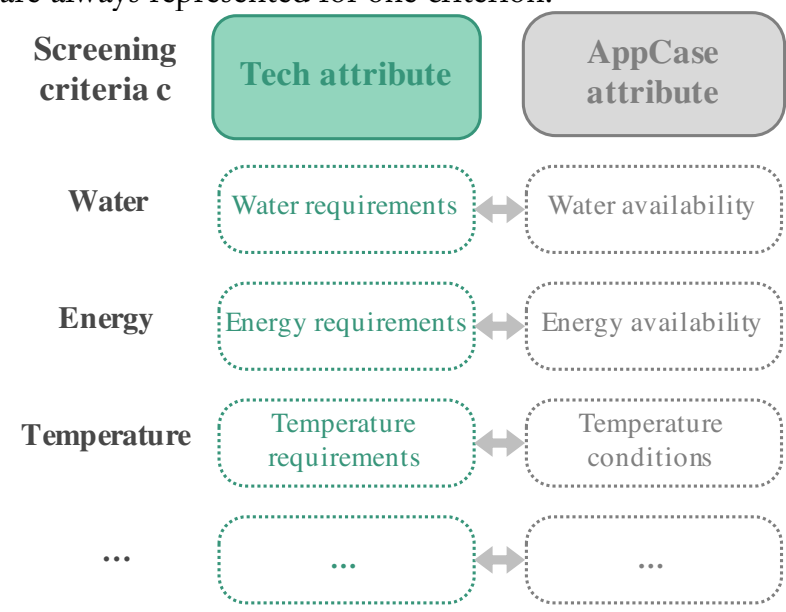

Figure 4: Examples of screening criteria and corresponding attributes used to assess the appropriateness of a set of potential technologies (Techs) for a specific application case (AppCase). For example, if a Tech has a high water requirement, but the water availability in the AppCase is very low, this Tech has limited appropriateness.

\subsubsection{Quantifying technology appropriateness}

The match of the Tech attribute with the AppCase attribute for a Tech $t$ and a criterion $c$ defines the appropriateness score, either as

$$
A S_{t, c}=P(p)=\int P(p \mid c) p(c) d c, \quad \text { Equation } 1
$$

if $\mathrm{p}(\mathrm{c})$ is a probability density function, or

$$
A S_{t, c}=P(p)=\sum_{c, \in \Omega} P(p \mid c) p\left(c^{\prime}\right) \quad \text { Equation } 2
$$

if $P(c)$ is a probability distribution function.

If a Tech $t$ has multiple criteria, the scores must be aggregated. The aggregation results in the technology appropriateness score $(T A S)$ :

$$
T A S_{t}=\sqrt[n]{\prod_{c=1}^{n} A S_{t, c}}
$$

Equation 3

It is important to note that screening criteria are different from performance criteria in SDM and MCDA, as they are used to quantify the suitability of an option in a given context and not to identify the best option (Eisenführ et al. 2010). Consequently, screening criteria do not necessarily apply to all options under assessment, whereas performance criteria must do so. For instance, water availability should not influence the $T A S_{t}$ of a Tech $t$ that operates completely independently of the water availability. However, the $T A S_{t}$ of this Tech $t$ can still be compared to the $T A S_{x}$ of another Tech $x$ which is waterreliant. Therefore, the aggregation function should allow for different numbers of criteria. We also require it to be equal to zero if at least one $A S_{t, c}$ is zero. The geometric mean (see Equation 3) fulfils these requirements (Langhans et al. 2014, Pollesch and Dale 2015, Rowley et al. 2012).

\subsubsection{Removing inappropriate Techs}

$T e c h s$ with a $T A S=O$ are totally inappropriate for the given AppCase and are therefore excluded. 


\subsection{Step 2: Building the SanSys option space (SanSys builder)}

\subsubsection{Building all possible sanitation systems from} Techs

A sanitation system (SanSys) is defined as a set of Techs which, in combination, manage sanitation products from the point of generation to a final point of reuse or disposal (adapted from Maurer et al. 2012 and Tilley et al. 2014b). The Techs contained in a SanSys can be organized in functional groups (FGs). We use the following FGs: toilet user interface $(\mathrm{U})$, on-site storage $(\mathrm{S})$, conveyance (C), transport (T), and reuse or disposal (D). A Tech belonging to $\mathrm{U}$ is always a source, while a Tech belonging to $\mathrm{D}$ is always a sink. Additional sources, such as tabs or drainage, are assigned to a sub-group of $U$ called $U_{\text {add. }}$. Each SanSys comprises at least one source and one sink and a number of compatible Techs in such a way that all products end up in another Tech or in a sink. The set of all valid SanSys is constructed on the basis of the appropriate Techs, as illustrated in Figure 5. A SanSys is valid if it fulfils the following criteria:

i. every output product of each Tech must be connected to another Tech that can take this product as its input,

ii. no Tech has inputs that are not connected to the output of another Tech.

These rules allow loops in a SanSys. However, loops between Techs are practically only possible if the infrastructures are situated close to each other. This leads to the additional constraint that

iii. loops are only allowed for the FG S or T either at the level of the premises (onsite) or at semicentralized treatment facilities (offsite).

The same product may occur onsite or offsite. In this case, it is treated as two different products for the generation of SanSys. For example, blackwater that is produced onsite (e.g. by a 'septic tank'), cannot feed into a centralized Tech (e.g. 'activated sludge'); it must first be transported by a transport Tech (e.g. 'conventional sewer'). For the generation of SanSys we distinguish between products and transported products in building the systems (i.e. 'blackwater' and 'transported blackwater').

The generation of SanSys requires some assumption and simplifications to be automated and generic enough to deal with all potential sanitation technologies. The main simplifications concern the way how the input and output streams are related to each other. Some Techs of the FG $\mathrm{C}$ take a varying number of input products that are then mixed together. To take this fact into consideration, the model defines a hierarchy of products according to their degree of pollution. When different products enter into such a Tech, the resulting output corresponds to the product which is defined to be the most polluted. For example, a conventional sewer fed with greywater and blackwater will produce blackwater. The same Tech fed with blackwater will also produce blackwater.

Another simplification concerns the generation of different Tech variations. The relations of different inand out-products to each other is defined as either (i) any possible combination ('OR'), (ii) their mutual exclusion ('XOR'); or their compulsory co-existence ('AND'). For example, a septic tank can have the following in-products: 'blackwater' OR 'greywater'; and has the following outproducts: 'sludge' AND 'effluent'. This results in three possible combination of in- and out-products: (i) blackwater, greywater -> effluent, sludge; (ii) blackwater -> effluent, sludge; (iii) greywater -> effluent, sludge. For the generation of SanSys we treat each of these possible combinations as a distinct Tech variation (see also supporting information $\mathrm{B}, \mathrm{SI}-\mathrm{B})$.

Creating all possible combination of Techs is not feasible as a very large number of combinations exist (see SI-B). Moreover, only a very small fraction of these possible combinations are valid SanSys. The SanSys builder we propose here provides an efficient heuristic designed to create all valid SanSys (see details in the SI-B). The functioning of the algorithm is illustrated in Figure 5.

\section{Potential SanSys options}

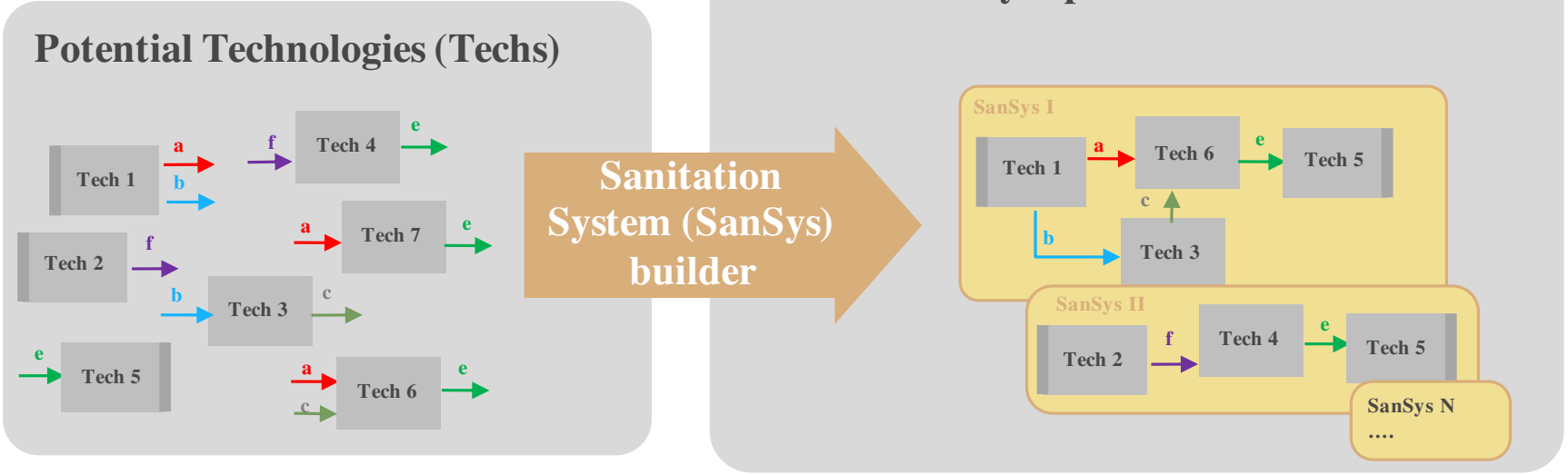

Figure 5: Concept underlying the efficient heuristic designed to build almost all valid sanitation systems (SanSys). The aim is to combine the set of appropriate technology options (Techs) in such a way that valid SanSys are generated (see text for the definition of valid SanSys). 


\subsubsection{Quantifying system appropriateness}

The SanSys appropriateness score $(S A S)$ is calculated by aggregating the TAS of every Tech of the system. Any aggregation function could be used. We propose a function that can either mimic the product of all $T A S$, the geometric mean, or a compromise between both:

$$
S A S_{S}=\prod_{i=1}^{\text {n.tech }} \prod^{\frac{1}{\alpha(\text { n.tech-1)+1 }}} \quad \text { Equation } 4
$$

where n.tech is the total number of Techs in a given system, and $\alpha \in[0,1]$.

A purely multiplicative aggregation $(\alpha=0)$ systematically penalizes SanSys with a large number of Techs. This contradicts the principle of allowing a broad range of SanSys in the decision option set. Using the geometric mean $(\alpha=1)$ is often not desirable neither, because a simple system should be preferred over a complex (long) one with the same performance. The smaller the factor $\alpha$ that is chosen, the longer the SanSys (i.e. SanSys with many Techs) are penalized.

\subsection{Step 3: Selection of decision options}

The set of all possible SanSys created in Step 2 may contain ten or even a hundred thousand systems. From these, we must select a subset $Q$ of potentially applicable decision options that will serve as an input for decisionmaking. We define two key characteristics for $Q$ :

i. The set contains the desired number of decision options. The absolute number of decision options depends on the specific SDM process and its ability to handle small or larger numbers of decision options.

ii. The set entails a diverse range of options. The integration of a high variability of different options opens up the decision space for the stakeholders and therefore increases the probability of finding a sustainable solution.

In a first step, the SanSys are grouped according to their system templates. A system template (ST) defines a class of SanSys with similar conceptual characteristics (see also Table 5). Then, the SanSys within each ST are assigned to clusters. For clustering, we use properties such as the number of technologies per SanSys and the K-medoids algorithm (e.g. Hastie et al. 2009). This algorithm is similar to the k-means but also allows non-Euclidian distance measures to be used. Finally, the SanSys with the highest score of each cluster is selected for $Q$. The number of clusters per ST is controlled by the number of options to be selected from an ST.

\subsection{User and stakeholder involvement}

The procedure is intended to be used by experts for identifying decision options in an SDM procedure such as CLUES. This includes data collection, the application of the appropriateness assessment, the system builder, and the identification of the set of selected decision options. The stakeholder involvement is particularly relevant for (i) the identification of screening criteria; (ii) the definition of potential Techs; (iii) the definition of system templates; (iv) and the definition of properties used to identify the selected set of options. The master list of screening criteria and the Tech database can be used as a point of departure (see also next section or directly DOI: 10.5281/zenodo.1092686).

\subsection{Implementation and data linking}

The assessment of the appropriateness of the Tech (section 2.2) was implemented in $\mathrm{R}$ ( $\mathrm{R}$ Development Core Team 2015). The code is freely accessible at https:/github.com/Eawag-SWW/TechAppA (v1.0). For the generation of the possible SanSys (section 2.3) and selection of $Q$ (section 2.4), Julia was chosen for performance reasons (Bezanson et al. 2017). The code is freely accessible

at https:/github.com/Eawag-SWW/SanitationSystemBuil der.jl (v1.0).

The data used and generated for this article is available at DOI: $10.5281 /$ zenodo.1092686. The database contains a set of 43 Techs and corresponding attribute functions. The database is a simple comma-separated text file and can be easily extended with any Tech as long as their inputs and outputs are known and information regarding the relevant screening criteria are available.

\subsection{Model sensitivity}

\subsubsection{Goal}

We perform a sensitivity analysis for the appropriateness assessment of Techs (step 1) and the selection of decision options (step 3). The generation of SanSys (step 2) does not require relevant parameters and is therefore not considered. The application in Katarniya (see section 3) is used as baseline scenario.

\subsubsection{Step 1: Appropriateness assessment of technology options}

The aim here is to see how the choice of screening criteria and attributes impacts the TAS and the corresponding ranking of Techs per FG. For example, criteria related to 'operation \& management' or 'skills' are often neglected. For this purpose, we perform the appropriateness assessment with different sets of screening criteria and compare the outcome with the baseline. Table 2 summarizes the changes in the set of criteria performed for the four runs presented 
Table 2: Overview of different computational runs implemented to evaluate the sensitivity of Step 1. Run 1.1 corresponds to the baseline scenario (application in Katarniya). Each run 1.2 to 1.4 corresponds to the removal of one or several criteria compared to the baseline. " $\checkmark$ " indicates that the criteria are included for the evaluation of the TAS, while "-" indicates that the criteria were not considered.

\begin{tabular}{llccc}
\hline Run & Name & Criterion management & $\begin{array}{c}\text { Criteria related to available } \\
\text { skills (construction, O\&M, } \\
\text { and design skills) }\end{array}$ & $\begin{array}{c}\text { Criteria related to O\&M } \\
\text { (frequency of O\&M, O\&M } \\
\text { skills) }\end{array}$ \\
\hline 1.1 & Baseline & $\checkmark$ & $\checkmark$ & $\checkmark$ \\
\hline 1.2 & No institutional aspects & - & $\checkmark$ & $\checkmark$ \\
\hline 1.3 & No capacity aspects & $\checkmark$ & - & $\checkmark$ \\
\hline 1.4 & No O\&M aspects & $\checkmark$ & $\checkmark$ & - \\
\hline
\end{tabular}

Table 3: Overview of the computational runs implemented to evaluate the sensitivity of Step 3. The columns show the numerical variations and model elements used for the generation of the set of selected sanitation system (SanSys) also called $\boldsymbol{Q}$. " $\boldsymbol{V}$ " indicates that the model element is included, while "-" indicates the element was not used.

\begin{tabular}{|c|c|c|c|c|c|c|}
\hline Run \# & Name & $\begin{array}{c}\text { Size of } Q \\
\text { (number of } \\
\text { selected SanSys } \\
\text { options) }\end{array}$ & $\begin{array}{c}\alpha \text { used to } \\
\text { compute the } S A S\end{array}$ & $\begin{array}{c}\text { Clustering } \\
\text { (according to } \\
\text { number of Techs } \\
\text { and number of } \\
\text { connections per } \\
\text { SanSys) }\end{array}$ & $\begin{array}{l}\text { Classification to } \\
\qquad \text { STs }\end{array}$ & $\begin{array}{l}\text { Selection based } \\
\text { on highest SAS }\end{array}$ \\
\hline 2.1 & Baseline & 36 & 0.5 & $\checkmark$ & $\checkmark$ & $\checkmark$ \\
\hline 2.2 & $\begin{array}{l}\text { Baseline (size of } \\
Q=8)\end{array}$ & 8 & 0.5 & $\checkmark$ & $\checkmark$ & $\checkmark$ \\
\hline 2.3 & $\alpha=0$ & 36 & 0 & $\checkmark$ & $\checkmark$ & $\checkmark$ \\
\hline 2.4 & $\alpha=1$ & 36 & 1 & $\checkmark$ & $\checkmark$ & $\checkmark$ \\
\hline 2.5 & No clusters & 36 & 0.5 & - & $\checkmark$ & $\checkmark$ \\
\hline 2.6 & $\begin{array}{l}\text { No system } \\
\text { templates }\end{array}$ & 36 & 0.5 & - & - & $\checkmark$ \\
\hline 2.7 & $\begin{array}{l}\text { Random within } \\
\text { templates }\end{array}$ & 36 & 0.5 & - & $\checkmark$ & - \\
\hline 2.8 & $\begin{array}{l}\text { Baseline (size of } \\
Q=4 \text { ) }\end{array}$ & 4 & 0.5 & $\checkmark$ & $\checkmark$ & $\checkmark$ \\
\hline 2.9 & $\begin{array}{l}\text { Baseline (size of } \\
Q=64 \text { ) }\end{array}$ & 64 & 0.5 & $\checkmark$ & $\checkmark$ & $\checkmark$ \\
\hline
\end{tabular}




\subsubsection{Step 3: Identification of decision options}

The aim here is to evaluate how different elements of Step 3 impact the median $S A S$ and the diversity of $Q$. The diversity of $Q$ is characterized by the average of the number of different STs, the number of different sources, the different numbers of Techs per SanSys, and the different numbers of connections per Tech within $Q$. The investigated elements are

- $\quad$ the size of $Q$,

- $\alpha$ used to compute the $S A S$,

- the clustering based on structural properties (numbers of Techs and number of connections per Tech per SanSys),

- the classification according to STs,

- the appropriateness assessment, and the resulting $S A S$.

\section{Example application}

To demonstrate the application, we selected a real case in Nepal. However, the case is not presented in its entire complexity.

\subsection{Application case}

\subsubsection{Description}

We applied our model to a water and sanitation project in Katarniya, a small town in the mid-western region of Nepal. Katarniya is very typical of an emerging small town in Nepal. It is characterized by rapid and unplanned growth, a weak institutional setting, and a lack of human and financial resources. Basic sanitation elements such as toilet infrastructure are present, but full sanitation systems are mostly absent. The project was planned and implemented by three partners of the Swiss Water and Sanitation Consortium (SWC). The aim of the project was to improve access to water and environmental sanitation for the central part of the town with about 1000 inhabitants. In order to improve the town's sanitation situation, an environmental sanitation plan was developed using CLUES (Lüthi et al. 2011).

\subsubsection{Data collection}

As model input data, we use the results from a household survey and an interaction workshop with the local community, both of which were conducted by the project in 2016. We complement this data with information that we collected during a field visit in May 2017.

\subsection{Step 1: Appropriateness assessment}

\subsubsection{Potential Techs}

Figure 6 illustrates all potential Techs used for the assessment. We rely on a restricted list of Techs for illustration purposes. Theoretically any number of Techs could be used as a point of departure. We have taken the list of potential Techs from the Compendium of Sanitation Systems and Technologies (Tilley et al. 2014b). To showcase the integration of novel options, we added 'vermi-composting' (Amoah et al. 2016, Lalander et al. 2013), 'struvite precipitation', and 'struvite application' (Dalecha 2012) to the list. These technologies have been tested in similar regions and shown to be promising.

3.2.2. Identification of screening criteria and attributes The screening criteria for the application case are derived from the master list in Table 1 . First, we validated this list by conducting a workshop with experts in Kathmandu in 2015. We noted very little disagreement between the locally brainstormed list and the master list provided. Second, based on individual consultations with some key workshop participants, we removed some criteria from the master list because they were either not relevant or contradicted the conditions listed in section 2.2.1. These criteria from Table 1 were removed:

- Nb. 11 : not relevant.

- $\quad$ Nb. 1, 2, 24, 25, 26, 30, and 31: involving major trade-offs which should be discussed among stakeholders.

- $\quad$ Nb. 5, 6, 7, 9, 14, 20, 21, 22 and 23: Not enough information available either for the AppCase or the Techs. 


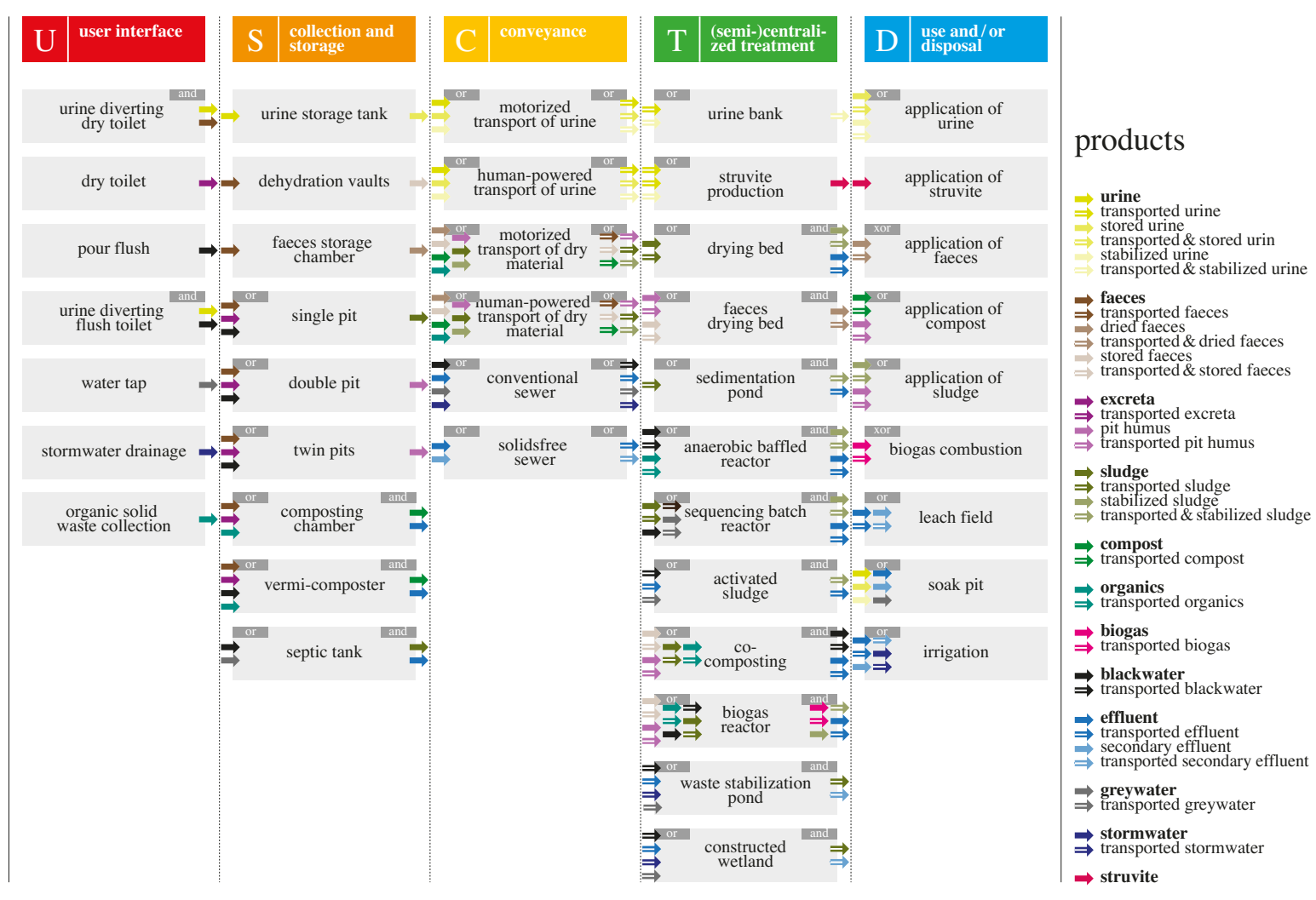

Figure 6: Overview of the sanitation technologies, products and functional groups (FGs) used in the example application in Nepal. Notes: (i) Storage (S) may also include (partial) treatment; (ii) Treatment (T) technologies may be applicable on-site (no transport required) or offsite; (iii) the model can also include non-toilet sources which allows the system boundaries to be extended (water tap, stormwater drainage, organic solid waste collection).

\subsubsection{Quantification of screening attributes}

To quantify the screening criteria, a pair of probability density and conditional probability functions is needed for each pair of Tech and AppCase attribute (see also section 2.2.2). These functions describe the requirements and the conditions that have to be matched. In principle, any uncertainty model and corresponding probability function could be used. However, the choice of probability function can have an impact on the model output and should be purely data-driven to represent the state of knowledge available at the structuring phase. The data sources generally available at the structuring phase include baseline reports, semi-structured interviews, reports from previous projects, and regional and national statistics. In the application case presented here, we found little information in these documents and therefore used rather simple probability functions: triangular, trapezoid, uniform, and categorical distributions. Based on similar experiences in other case studies (not presented here), we recommend working with such simple functions except where good reason or data exists to use more sophisticated models (e.g. a normal or beta distribution). Expert knowledge is required to identify a probability function that embraces all relevant data sources considering their potential inconsistency. Here we provide some examples how the functions are applied based on available input data. The categorical function is a non-continuous function. It is best applied when the data contains categories and a value for each category is available: e.g. $30 \%$ of population have low access to water, $50 \%$ have moderate access, and 20\% have high access (categorical density function). The uniform function is the simplest model and requires only an upper and lower level: e.g. Tech $\mathrm{X}$ has a performance of $100 \%$ between $5^{\circ} \mathrm{C}$ to $35^{\circ} \mathrm{C}$ (conditional uniform probability function). The triangular function requires a minimum, maximum, and a mean value: e.g. the temperature in the AppCase varies between 5 and $42^{\circ} \mathrm{C}$ with a mean at $28^{\circ} \mathrm{C}$ (triangular density function). The trapezoidal function requires four values including the minimum, the maximum, and the two modes in between: e.g. the performance of a Tech $\mathrm{Y}$ starts at $-5^{\circ} \mathrm{C}$, is $100 \%$ between 5 and $25^{\circ} \mathrm{C}$ and then decreases until $50^{\circ} \mathrm{C}$ (trapezoidal conditional probability function).

Table 4 shows the final list of screening criteria, the corresponding attributes, and the type of probability function used in the application in Katarniya for each attribute. The use of ' $d$-' at the beginning of the function name refers to the density function, ' $p$-' refers to the conditional probability, 'cat' stands for a categorical function, 'triangle' refers to a triangular distribution, 'range' refers to a uniform distribution, and 'trapez' refers to a trapezoidal distribution. All the AppCase data and the Tech data are available in the associated data (DOI: 10.5281/zenodo.1092686). 
Table 4: Overview of screening criteria, corresponding attributes and the type of uncertainty functions used to quantify the attributes.

\begin{tabular}{|c|c|c|c|c|}
\hline Screening criteria & Tech attribute and probal & $y$ function & AppCase attribute and pro & unction \\
\hline Water supply & Water requirements & pcat & Water availability & dcat \\
\hline Energy supply & Energy requirements & ptriangle & Energy availability & drange \\
\hline Frequency of O\&M & Frequency of O\& M & $\begin{array}{l}\text { dtrianlge or } \\
\text { drange }\end{array}$ & O \& M capacity & prange \\
\hline Temperature & Temperature requirements & $\begin{array}{l}\text { prange, ptrapez, } \\
\text { or ptriangle }\end{array}$ & Temperature range & dtriangle \\
\hline Flooding & Flooding tolerance & ptrapez & Flooding occurrence & drange \\
\hline Vehicular access & Access requirements & $\begin{array}{l}\text { ptrapez or } \\
\text { prange }\end{array}$ & Accessibility of households & dtrapez \\
\hline Slope & Slope requirements & ptrapez & Slope distribution & dtriangle \\
\hline $\begin{array}{l}\text { Soil type / hydraulic } \\
\text { conductivity }\end{array}$ & Soil type requirements & pcat & Soil type occurrence & dcat \\
\hline Groundwater depth & Groundwater depth requirements & $\begin{array}{l}\text { prange, or } \\
\text { ptrapez }\end{array}$ & Groundwater depth occurrence & dtrapez \\
\hline Excavation & Excavation requirements & pcat & Ease of excavation & dcat \\
\hline Construction skills & Construction skills requirements & dtriangle & Construction skills availability & ptrapez \\
\hline Design skills & Design skills requirements & dtriangle & Design skills availability & ptrapez \\
\hline O\&M Skills & O\&M skills requirements & dtriangle & O\&M skills availability & ptrapez \\
\hline Management & $\begin{array}{l}\text { Required management level } \\
\text { (household, shared, public) }\end{array}$ & pcat & Preferred management level & dcat \\
\hline Spare parts & Spare parts requirements & deat & Spare parts supply & pcat \\
\hline
\end{tabular}

\subsubsection{Quantifying TAS}

The AppCase attributes and corresponding functions in Table 4 were parametrized with the data collected in Katarniya (see 3.1.2 Data collection). The Tech attributes for all Techs in Figure 6 were quantified on the basis of the literature and our own expert estimations.

\subsection{Step 2: Generation of sanitation systems}

We use 37 Techs from the 43 shown in Figure 6 to build the SanSys option space. We have excluded some Techs from the system generation in order to limit the size of the option space and to make the example application more illustrative. The excluded Techs are all Techs from the FG $U_{\text {add }}$, as well as the Techs struvite production, struvite application, and irrigation. To compute the $S A S$, we use $\alpha=0.5$.

\subsection{Step 3: Selection of decision options}

\subsubsection{Classification into system templates}

Table 5 shows the properties and STs which we use for classifying the SanSys. The Compendium of Sanitation Systems and Technologies (Tilley et al. 2014b) serves as the inspiration for the STs used. However, we defined the STs provided further by specifying distinctive profiles and refining some STs. For sixteen STs sorted into four groups, we use nine properties. 
Table 5: System templates (ST) used to characterize the sanitation system (SanSys) option space. The STs are adapted from Tilley et al. (2014b). Each of the 16 ST has a unique profile defined by a value for the nine properties. ' 1 ' means that the property applies (e.g. 'the systems do have dry material production"); 0 means that the properties do not apply (e.g. "there is no dry material"); and 'not defined' (n.d.) means that the property does not apply to this ST.

\begin{tabular}{|c|c|c|c|c|c|c|c|c|c|c|c|c|}
\hline \multirow[b]{2}{*}{$\hat{\mathbf{Z}}$} & \multirow[b]{2}{*}{ 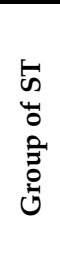 } & \multirow[b]{2}{*}{ STs } & \multicolumn{10}{|l|}{ ST profiles } \\
\hline & & & $\begin{array}{l}\text { Property / detailed } \\
\text { description of ST }\end{array}$ & $\begin{array}{c}\text { Dry } \\
\text { material } \\
\text { (pit } \\
\text { humus, } \\
\text { compost, } \\
\text { dried or } \\
\text { stored } \\
\text { faeces) }\end{array}$ & $\begin{array}{l}\text { Onsite } \\
\text { sludge } \\
\text { productio } \\
n\end{array}$ & Urine & $\begin{array}{l}\text { Blackwat } \\
\quad \text { er }\end{array}$ & $\begin{array}{l}\text { Transpor } \\
\text { ted black- } \\
\text { or brown- } \\
\text { water }\end{array}$ & $\begin{array}{l}\text { Effluent } \\
\text { transport }\end{array}$ & Biogas & $\begin{array}{l}\text { Transpor } \\
\text { ted biogas }\end{array}$ & $\begin{array}{l}\text { With a } \\
\text { single pit } \\
\text { onsite }\end{array}$ \\
\hline क. & $\frac{0}{a}$ & $\begin{array}{l}\text { Dry onsite storage } \\
\text { without treatment }\end{array}$ & $\begin{array}{l}\text { This includes simple onsite storage } \\
\text { of dry or wet toilet products with } \\
\text { sludge production such as a single } \\
\text { pit or a single ventilated improved } \\
\text { pit latrine (VIP) }\end{array}$ & n.d. & 1 & n.d. & n.d. & 0 & n.d. & 0 & 0 & 1 \\
\hline 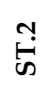 & के & $\begin{array}{l}\text { Dry onsite storage and } \\
\text { treatment }\end{array}$ & $\begin{array}{l}\text { Excreta are stored onsite and } \\
\text { transformed to either pit humus or } \\
\text { compost. }\end{array}$ & 1 & 0 & 0 & 0 & 0 & n.d. & 0 & 0 & 0 \\
\hline$\stackrel{m}{\omega}$ & & $\begin{array}{l}\text { Dry onsite storage } \\
\text { without sludge with } \\
\text { urine diversion }\end{array}$ & $\begin{array}{l}\text { Mainly urine diversion dry toilets } \\
\text { (UDDTs) or dry composting } \\
\text { systems with urine diversion. }\end{array}$ & 1 & 0 & 1 & 0 & 0 & n.d. & 0 & 0 & n.d. \\
\hline 㫄 & $\stackrel{\mathscr{\Xi}}{5}$ & $\begin{array}{l}\text { Onsite blackwater } \\
\text { without sludge and } \\
\text { with urine diversion }\end{array}$ & $\begin{array}{l}\text { Mainly onsite composting systems } \\
\text { with urine diversion }\end{array}$ & 1 & 0 & 1 & 1 & 0 & n.d. & 0 & 0 & 0 \\
\hline$\stackrel{\text { ?ִ }}{\omega}$ & & $\begin{array}{l}\text { Offsite blackwater } \\
\text { treatment with urine } \\
\text { diversion }\end{array}$ & $\begin{array}{l}\text { Sewer systems with urine } \\
\text { diversion }\end{array}$ & n.d. & n.d. & 1 & 1 & 1 & n.d. & 0 & 0 & n.d. \\
\hline$\stackrel{\varphi}{\omega}$ & & $\begin{array}{l}\text { Onsite biogas with } \\
\text { effluent infiltration }\end{array}$ & $\begin{array}{l}\text { Biogas reactor where effluent goes } \\
\text { to onsite infiltration (soak pit). }\end{array}$ & n.d. & n.d. & n.d. & n.d. & 0 & 0 & 1 & 0 & n.d. \\
\hline 宛 & $\underset{\pi}{\pi}$ & $\begin{array}{l}\text { Onsite biogas with } \\
\text { effluent transport }\end{array}$ & $\begin{array}{l}\text { Biogas reactor where effluent goes } \\
\text { to a simplified sewer. }\end{array}$ & n.d. & n.d. & n.d. & n.d. & 0 & 1 & 1 & 0 & n.d. \\
\hline$\stackrel{\infty}{\omega}$ & की & $\begin{array}{l}\text { Offsite biogas without } \\
\text { blackwater transport }\end{array}$ & $\begin{array}{l}\text { This mainly concerns the transport } \\
\text { of pit humus or sludge (e.g. from } \\
\text { septic tanks) to a (semi-centralized } \\
\text { co-digestion facility }\end{array}$ & n.d. & n.d. & n.d. & n.d. & 0 & n.d. & 1 & 1 & n.d. \\
\hline$\stackrel{9}{\omega}$ & & $\begin{array}{l}\text { Offsite biogas with } \\
\text { blackwater transport }\end{array}$ & $\begin{array}{l}\text { Co-digestion of blackwater collected } \\
\text { through sewer lines }\end{array}$ & n.d. & n.d. & n.d. & 1 & 1 & n.d. & 1 & 1 & n.d. \\
\hline$\stackrel{\circ}{\stackrel{1}{\oplus}}$ & & $\begin{array}{l}\text { Onsite blackwater } \\
\text { without sludge and } \\
\text { with effluent } \\
\text { infiltration }\end{array}$ & $\begin{array}{l}\text { Blackwater is stored, dewatered, } \\
\text { and transformed to compost or pit } \\
\text { humus (e.g. twin-pits); effluent } \\
\text { goes to a soak pit or similar. }\end{array}$ & 1 & 0 & 0 & 1 & 0 & 0 & 0 & 0 & 0 \\
\hline 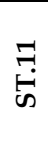 & & $\begin{array}{l}\text { Onsite blackwater } \\
\text { without sludge and } \\
\text { with effluent transport }\end{array}$ & $\begin{array}{l}\text { Blackwater is stored, dewatered } \\
\text { and transformed to compost or pit } \\
\text { humus (e.g. twin pits); effluent } \\
\text { goes to a simplified sewer or } \\
\text { similar. }\end{array}$ & 1 & 0 & n.d. & 1 & 0 & 1 & 0 & 0 & 0 \\
\hline 光 & 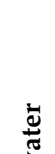 & $\begin{array}{l}\text { Onsite blackwater with } \\
\text { sludge and effluent } \\
\text { infiltration }\end{array}$ & \begin{tabular}{|l|} 
Mainly septic tank or similar \\
options (which are not just for \\
storage but also involve some sort \\
of basic treatment); effluent goes to \\
a soak pit or similar. \\
\end{tabular} & n.d. & 1 & n.d. & 1 & 0 & 0 & 0 & 0 & 0 \\
\hline$\stackrel{m}{\infty}$ & $\begin{array}{l}\frac{\pi}{3} \\
\frac{\pi}{0} \\
0\end{array}$ & $\begin{array}{l}\text { Onsite blackwater with } \\
\text { sludge and effluent } \\
\text { transport }\end{array}$ & $\begin{array}{l}\text { Mainly septic tank or similar } \\
\text { options (which are not just for } \\
\text { storage but also involve some basic } \\
\text { treatment); effluent goes to a } \\
\text { simplified sewer or similar. }\end{array}$ & n.d. & 1 & n.d. & 1 & 0 & 1 & 0 & 0 & 0 \\
\hline$\stackrel{+5}{\leftrightarrow}$ & & $\begin{array}{l}\text { Onsite blackwater } \\
\text { treatment with effluent } \\
\text { infiltration }\end{array}$ & $\begin{array}{l}\text { Concerns compact onsite } \\
\text { wastewater treatment units such as } \\
\text { SBR; effluent goes to a soak pit or } \\
\text { similar. }\end{array}$ & 0 & 0 & n.d. & 1 & 0 & 0 & 0 & 0 & 0 \\
\hline 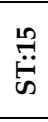 & & $\begin{array}{l}\text { Onsite blackwater } \\
\text { treatment with effluent } \\
\text { transport }\end{array}$ & $\begin{array}{l}\text { Concerns compact onsite } \\
\text { wastewater treatment units such as } \\
\text { SBRs; effluent goes to a simplified } \\
\text { sewer or similar. }\end{array}$ & 0 & 0 & n.d. & 1 & 0 & 1 & 0 & 0 & 0 \\
\hline 先 & & $\begin{array}{l}\text { Offsite blackwater } \\
\text { treatment }\end{array}$ & $\begin{array}{l}\text { Everything goes to a } \\
\text { (semi-)centralized system through } \\
\text { sewer lines. }\end{array}$ & n.d. & 0 & 0 & 1 & 1 & n.d. & 0 & 0 & 0 \\
\hline
\end{tabular}




\subsubsection{Clustering}

For clustering within the STs, we use two properties: (i) the number of Techs per SanSys, and (ii) the mean number of connections per Tech within a SanSys as a measure of complexity.

\subsubsection{Selection of SanSys options}

We define the number of SanSys in $Q$ as 36 and distribute these 36 options across the STs. The distribution is proportional to the $90 \%$ quantile of $S A S$ within each ST under the condition that each ST is represented at least once in $Q$.

\subsection{Results of the application case}

\subsubsection{Step 1: Appropriateness assessment}

The histogram of the TAS per FG may be seen in Figure 7: It shows that for this case the selection of Tech in the FG $\mathrm{C}$ and $\mathrm{T}$ is most relevant, while all Techs in $\mathrm{U}, \mathrm{S}$, and $\mathrm{D}$ perform similarly well. None of the Techs perform very badly because those selected have already been shown to be applicable in similar regions.

It is illustrative to identify those criteria that influence the $T A S$ the most. Figure 8 shows the distribution of the $A S_{t, c}$ grouped per FG. From a visual analysis, we can see that the management and to a lower extent construction skills, temperature range, and slope are the most variable criteria and are therefore mainly responsible for the diversity of TAS shown in the previous figure (Figure 7).

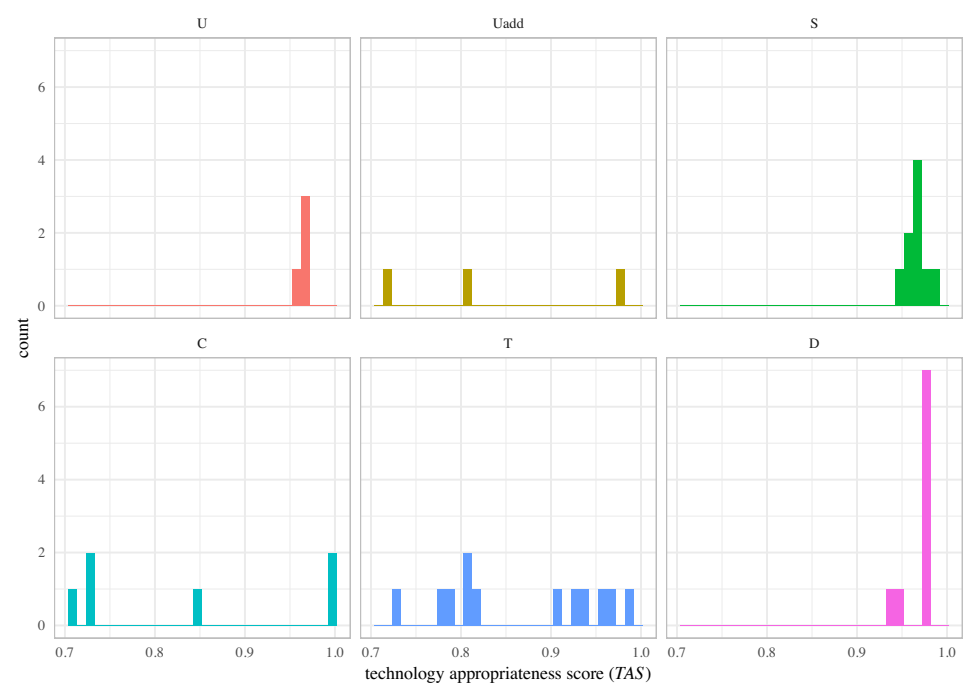

Figure 7: Histogram of technology appropriateness scores (TAS) grouped per functional group (U: user interface; $\mathrm{U}_{\text {add: }}$ user interface other than toilet; S: collection and storage; C: conveyance; T: (semi-)centralized treatment; D: reuse or disposal). Please be aware that the abscissae start at 0.7 and not at the origin.

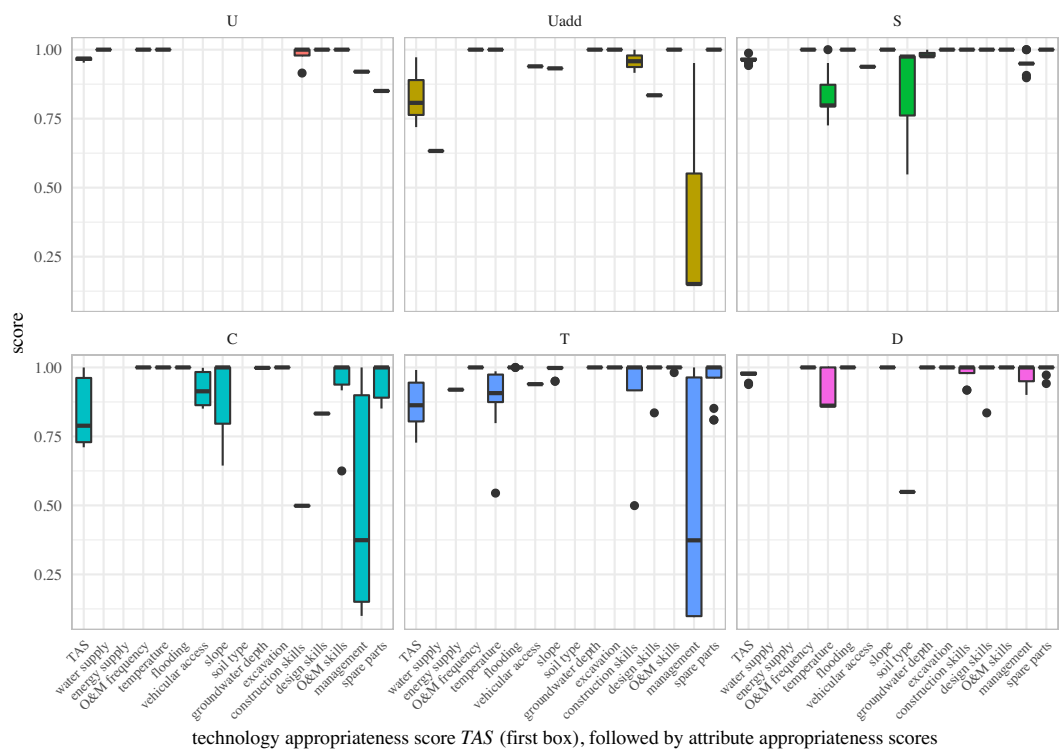

Figure 8: Boxplot of technology appropriateness scores $(T A S)$ and criteria appropriateness scores $\left(A S_{t, c}\right)$ grouped per functional group (FG, U: user interface; $\mathrm{U}_{\text {add: }}$ user interface other than toilet; S: collection and storage; C: conveyance; T: (semi-)centralized treatment; D: reuse or disposal). The first box in each FG always corresponds to the $T A S$ and the subsequent boxes to the $A S_{t, c}$. A higher wider box indicates a higher variability of the $T A S$, respectively the $\mathrm{i}$. The figure allows to visually identifying those FGs with more variability in terms of $T A S$, and to identify those $A S_{t, c}$ that can be accounted for this higher variability. 


\subsubsection{Step 2: System generation}

In total, 17,955 possible SanSys can be generated. These are distributed as follows: 2,166 SanSys for the urine diversion dry toilets (UDDTs), 380 for dry toilets, 1,531 for pour-flush toilets and 13,878 for urine diversion flush toilets (UDFTs). UDDTs and UDFTs have more SanSys because these sources generate two output products (urine and faeces or blackwater), which greatly increases the number of Techs per SanSys and consequently the number of possible combinations. The computation time on an average desktop computer was approximately 14 minutes.

The number of Techs per SanSys varies between 3 and 14. Different numbers of Techs per SanSys are represented in all $S A S$ ranges, indicating that $\alpha=0.5$ is probably a reasonable choice. In the case of higher $\alpha$ (e.g. $\alpha=1$, no penalization of length), we would have more long systems with a higher $S A S$ and for a lower $\alpha$ (e.g. $\alpha$ $=0$ ) we would mainly see short systems with a high $S A S$.

\subsubsection{Step 3: Option selection}

The histograms of all SAS grouped according to the system templates (STs, see Table 5) are shown in Figure
9. The figure illustrates how the total number of SanSys per ST varies. This number depends on the Techs available for a given ST and on the number of products arising from these Techs. Both have an effect on the number of possible Tech combinations and thus on the number SanSys variations.

We distribute the 36 options to be selected among the STs proportional to the $90 \%$ quantile of $S A S$ within each ST under the condition that each ST is represented at least once in S. The $90 \%$ quantile of $S A S$ within each ST is illustrated by the red line in Figure 9. From the STs with a higher $90 \%$ quantile, three SanSys are selected (ST.2, ST.4, ST.6, and ST.10). Only two SanSys are selected from all other STs.

In Figure 10 we show the number of Techs per SanSys and the number of connection per Tech. SanSys with similar characteristics are grouped in clusters of same size within a ST (see also section 2.4). These clusters are indicated by the different colours. The SanSys with the best $S A S$ in each cluster is selected to be in $Q$ (marked by a cross).

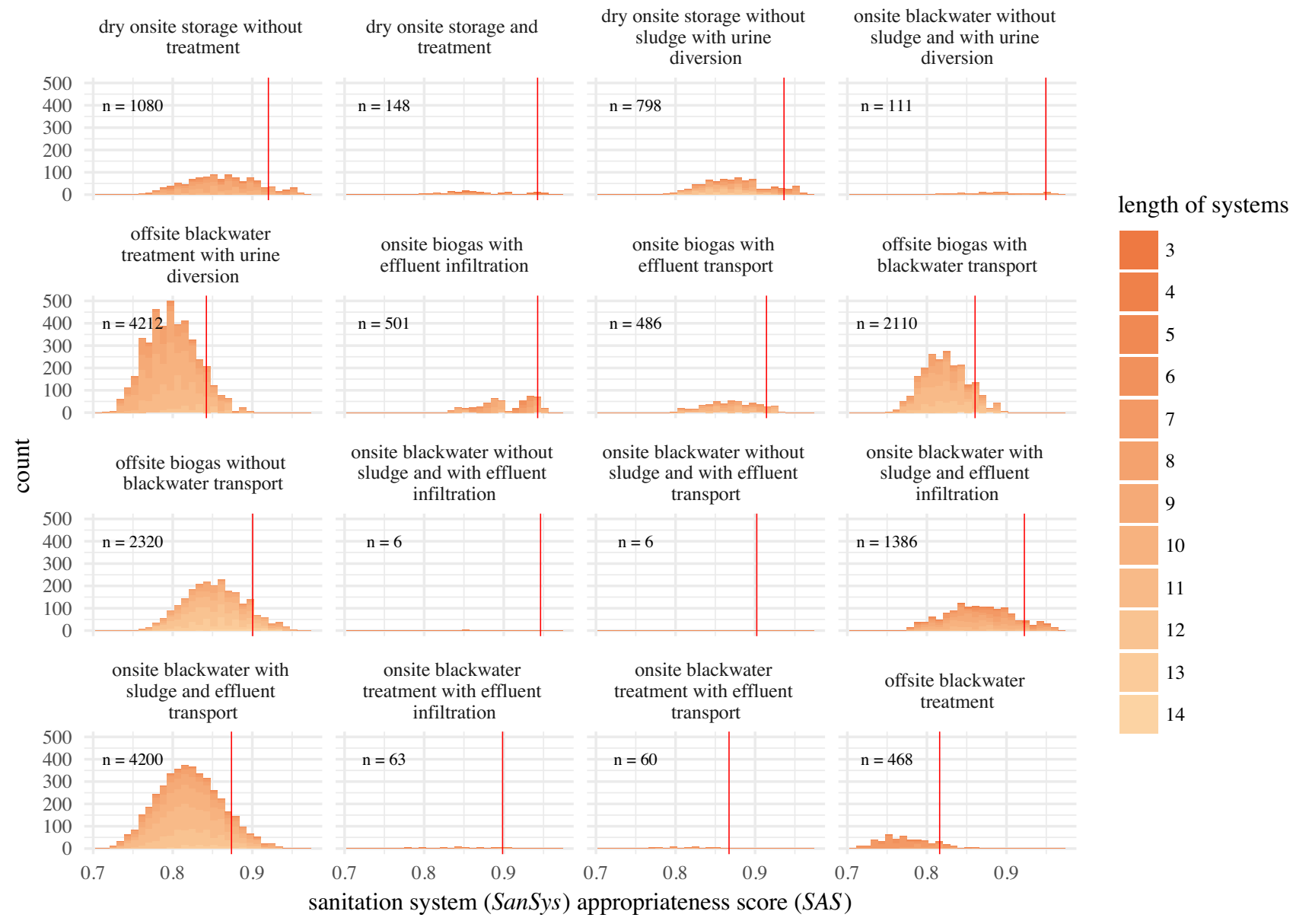

Figure 9: Histogram of sanitation system (SanSys) appropriateness scores (SAS) grouped per system template (ST). The numbers of SanSys per ST are also indicated (n). The $90 \%$ quantile of $S A S$ within each ST is used to distribute the total number of SanSys to be selected and is indicated by the red line. 


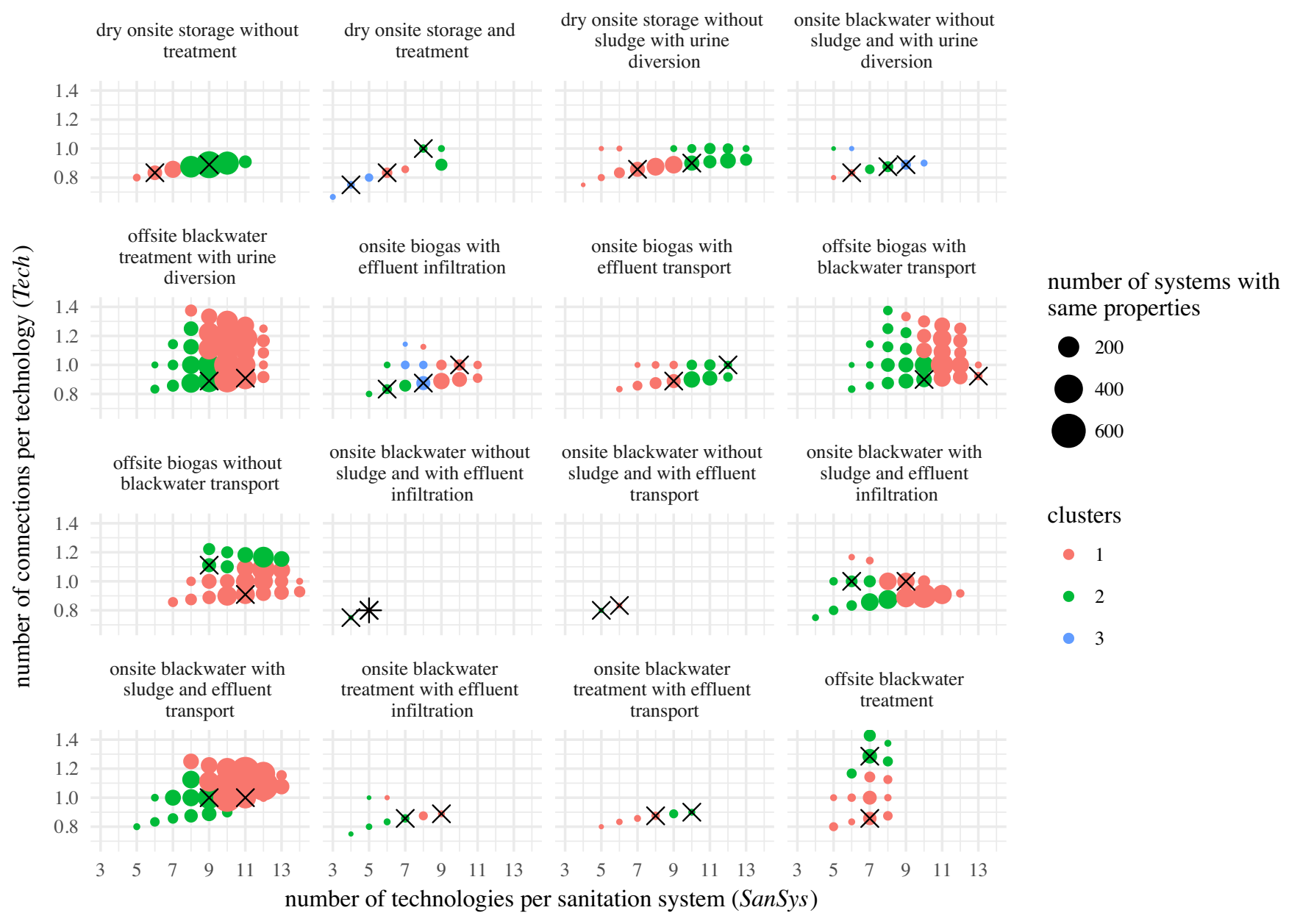

Figure 10: Count plot of the number of Techs per SanSys and the number of connection per Tech of all sanitation system (SanSys) options grouped per system template (ST). SanSys with similar characteristics are grouped in clusters of same size within an FG (indicated by the different colour). The size of the circles indicates the number of SanSys with exactly the same characteristics. The system with the best $S A S$ (the most appropriate SanSys) in each cluster is selected to be used in the decision-making process (marked by a cross).

Four examples of selected SanSys are illustrated in Figure 11 (see SI-C for the others). The systems (a), (b), and (c) are examples of SanSys that have been successfully implemented in the region of the case study. The systems are diverse, as (a) is onsite and dry, (b) onsite wet, producing biogas, and (c) is an offsite wet blackwater system involving centrally-managed natural wastewater treatment. The SanSys given in (d) is a novel option for the context of Nepal. It combines onsite vermicomposting with urine diversion and centralized urine treatment and allows recovery of nutrients and organic matter in the form of stabilized urine and compost. This system has shown high potential in similar regions (Amoah et al. 2016), and it is therefore highly appropriate to include it in the set of decision options 
a)

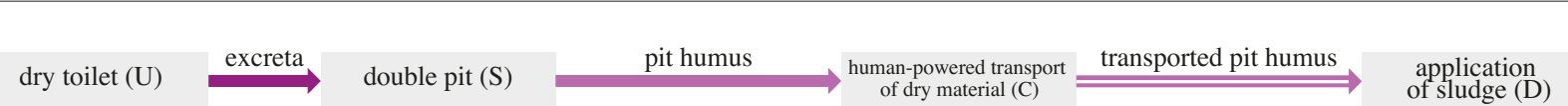

b)

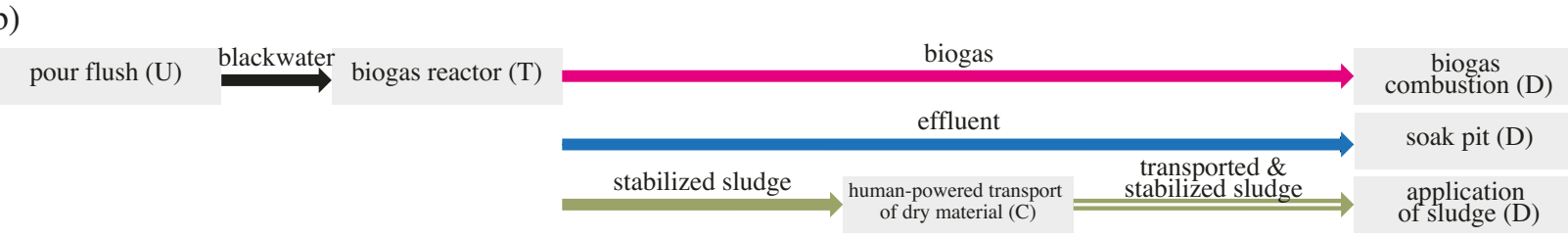

c)

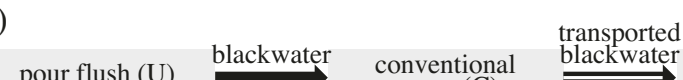
pour flush (U) $\stackrel{\text { blackwater }}{\longrightarrow} \begin{gathered}\text { conventional } \\ \text { sewer (C) }\end{gathered}$ constructed
wetland $(T)$
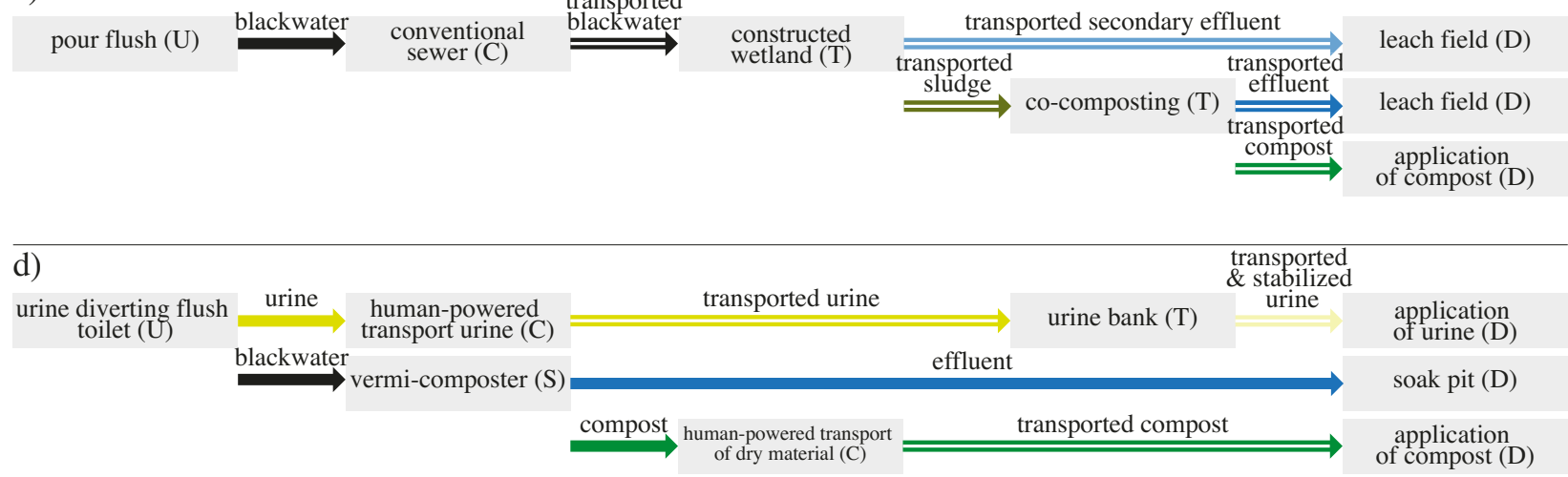

Figure 11: Four examples of sanitation systems (SanSys) selected for use in the decision-making process (from a total of 36; see supporting information for the others). Each box represents a technology (Tech). The arrows indicate the sanitation products. The letter in the parenthesis indicates the functional group. Systems (a), (b), and (c) are very different but are all quite common in the region. System (d) is a novel system based on vermi-composting. (a) System template 2 (ST.2): dry onsite storage and treatment), $S A S=0.966$; (b) ST.6 onsite biogas with effluent infiltration, $S A S=0.938$; (c) ST.16 offsite blackwater treatment, $S A S=0.857$; (d) ST.4 onsite blackwater without sludge and with urine diversion, $S A S=0.958$.

\subsection{Results of sensitivity evaluation}

\subsubsection{Step 1: Appropriateness assessment of technology options}

The omission of some criteria influences the ranking of the Tech as the impact on the TAS is not the same for different Techs. To quantify the change in the ranking, we counted the number of Techs that either moved up or down compared to the baseline (run 1.1).

Table 6 shows the count of changes per FG and in total. The results are analysed separately for each FG, as only Techs within the same FG are true alternatives to each other. There is a total of 26 changes for run 1.2 (without management), 22 for run 1.3 (without criteria related to skills), and 8 for run 1.4 (without criteria related to O\&M). The results compare well with Figure 8, showing the high impact of the management screening criterion (run 1.2) and the criteria related to skills (construction, O\&M, and design skills, run 1.3). The omission of the criteria frequency of O\&M and O\&M skills also has an impact, although this is much lower (

Table 6, run 1.4). The criteria relating to O\&M also have an impact, but it is rather lower. The removal of the management criterion (run 1.2) also resulted in a lower variance of the TAS (not shown in the table, see associated data at DOI: 10.5281/zenodo.1092686 for full results), showcasing the importance of this criteria to enhance the significance of the rankings

Table 6: Results from the sensitivity analysis of runs 1.2 to 1.3 . Run 2.1 serves as a baseline (not shown). The results are shown as changes in position of the ranking of the Techs within a functional group (FGs) according to their technology appropriateness score $T A S$. The results are analysed separately for each FG, as only Techs within the same FG are true alternatives to each other. 


\begin{tabular}{|c|c|c|c|c|}
\hline & & & Run & \\
\hline$F G$ & $\begin{array}{c}\text { Number of } \\
\text { Techs }\end{array}$ & 1.2 & $\begin{array}{l}\text { Without construction skills, } \\
\text { O\&M skills, and design skills }\end{array}$ & $\begin{array}{l}1.4 \\
\text { Without criteria related } \\
\text { frequency of } O \& M \text {, and } \\
\text { O\&M skills }\end{array}$ \\
\hline $\mathbf{U}$ & 4 & 0 & 4 & 0 \\
\hline $\mathbf{S}$ & 9 & 5 & 3 & 2 \\
\hline C & 6 & 3 & 1 & 3 \\
\hline $\mathbf{T}$ & 12 & 3 & 5 & 3 \\
\hline D & 9 & 7 & 8 & 2 \\
\hline Total & 43 & 26 & 22 & 8 \\
\hline
\end{tabular}

\subsubsection{Step 3: Option selection}

The five elements that were varied in the analysis (see section 2.7.1.2) have different impacts on $Q$.

Table 7 shows the characteristics of the Qs generated in the runs 2.1 to 2.7. The $Q s$ are evaluated by the median $S A S$, the diversity as a function of number of different sources within $Q$, the number of different STs, the number of different numbers of technologies per system, and the number of different numbers of connections per Tech (see also section 2.7.1.2). Figure 12 highlights the diversity and the median $S A S$ of the $Q s$ obtained with the different runs. Figure 13 highlights the impact of the size (number of selected SanSys) on the diversity of $Q$. In the following, we discuss the influence of all five evaluated elements on the median $S A S$ and the diversity.

\subsubsection{Size of $\mathbf{Q}$}

The baseline (run 2.1) has a size of $Q=36$ compared to 8,4 , and 64 for runs $2.2,2.8$, and 2.9 respectively. The SanSys are selected in decreasing order of $S A S$, so that a smaller $Q$ will always result in a higher median $S A S$ (Figure 12). As shown in Figure 13, the diversity increases with the size of $Q$. The benefit of a large $Q$ for diversity tempers as soon as the size of the $Q$ exceeds the total number of STs defined (16 STs in our case, see also Table $5)$.

\subsubsection{2. $a$}

A small $\alpha$ penalizes long systems, so that $\alpha=0$ (run 2.3) results in a lower number of different numbers of Techs (see SI-D). This is reflected in the diversity which is 9.75 for $\alpha=0$ (run 2.3), 10.5 for $\alpha=0.5$ (run 2.1), and 10.75 for $\alpha=1$ (run 2.4, Figure 12). The term $\alpha$ also shifts the scale of the $S A S$ to lower values, so that the median SAS is not directly comparable. It is interesting to note that the decrease in diversity, as well as the shifting effect are both more pronounced if $\alpha$ is reduced from 0.5 to 0 , compared to an increase from 0.5 to 1 . This indicates that $\alpha=0.5$ provides a good balance between the penalization of long systems and maintaining high diversity.

\subsubsection{Clustering to structural properties}

The clustering itself, as shown by run 2.5 , has little impact on the diversity or the median of $S A S$.

\subsubsection{Classification to system templates}

In run 2.6, we select the 36 SanSys with the highest $S A S$, ignoring the STs and without clustering. This obviously results in a higher $S A S$ (Figure 12), although the impact is small. On the other hand, the diversity is strongly impacted, as only five STs remain represented in $Q$.

\subsubsection{Use of the SAS}

In run 2.7, we use STs to classify and then randomly (independently of $S A S$ ) select the number of options from each ST. This has a high impact on the median $S A S$ (Figure 12), whereas the decrease of diversity is negligible. 
Table 7: This table shows the characteristics of diversity and the median system appropriateness score (SAS) of the sets of selected sanitation systems (SanSys) $\boldsymbol{Q}$ resulting from runs 2.1 to 2.7 of the sensitivity analysis of step 3 . The characteristics of the different runs are shown in section 2.7.1.2). In summary, the highest impact on the diversity and median $S A S$ of $\boldsymbol{Q}$ can be observed by the size of $\boldsymbol{Q}$, the use of STs (all except run 2.6), and the use (or not) of the SAS (all except run 2.7).

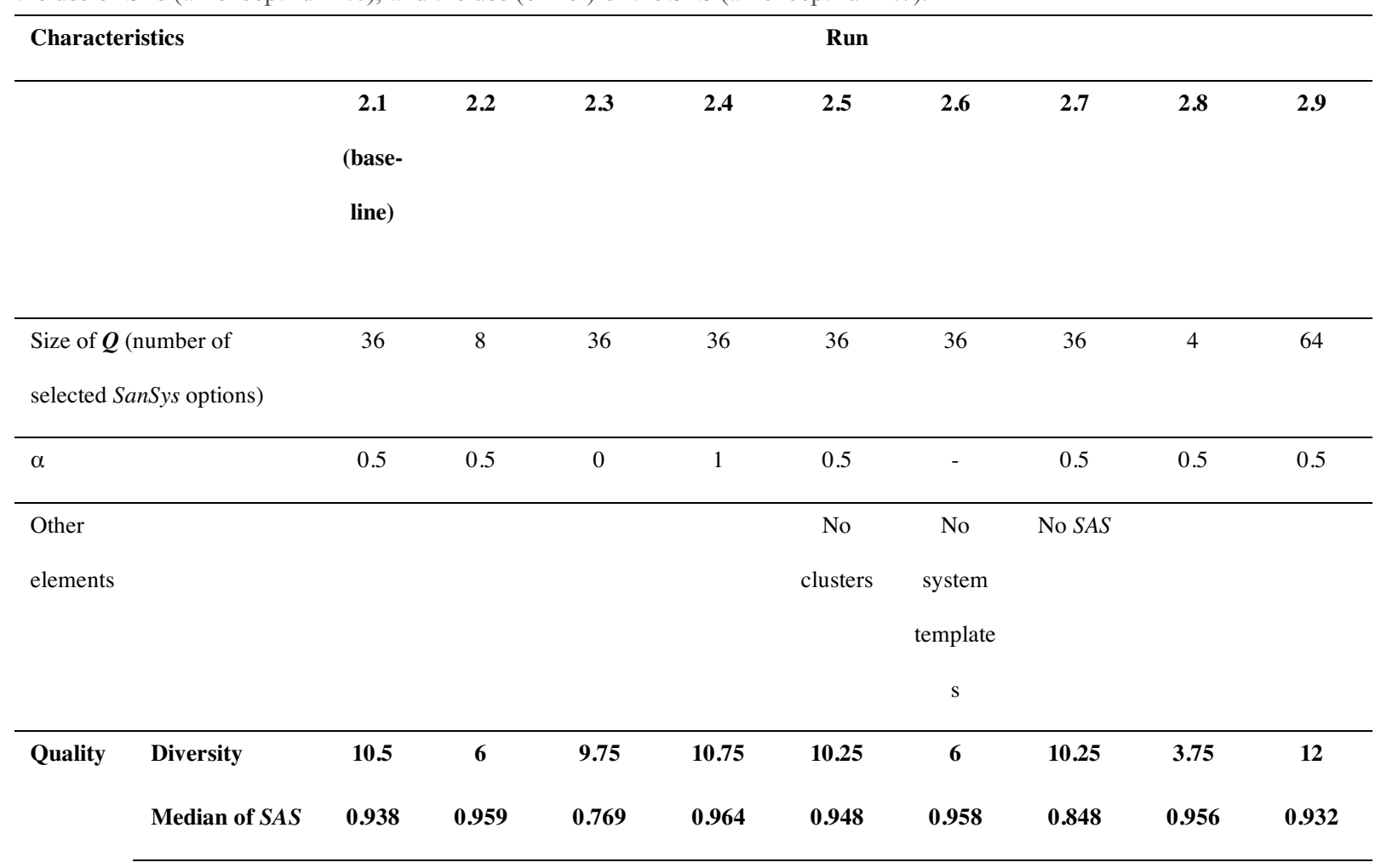

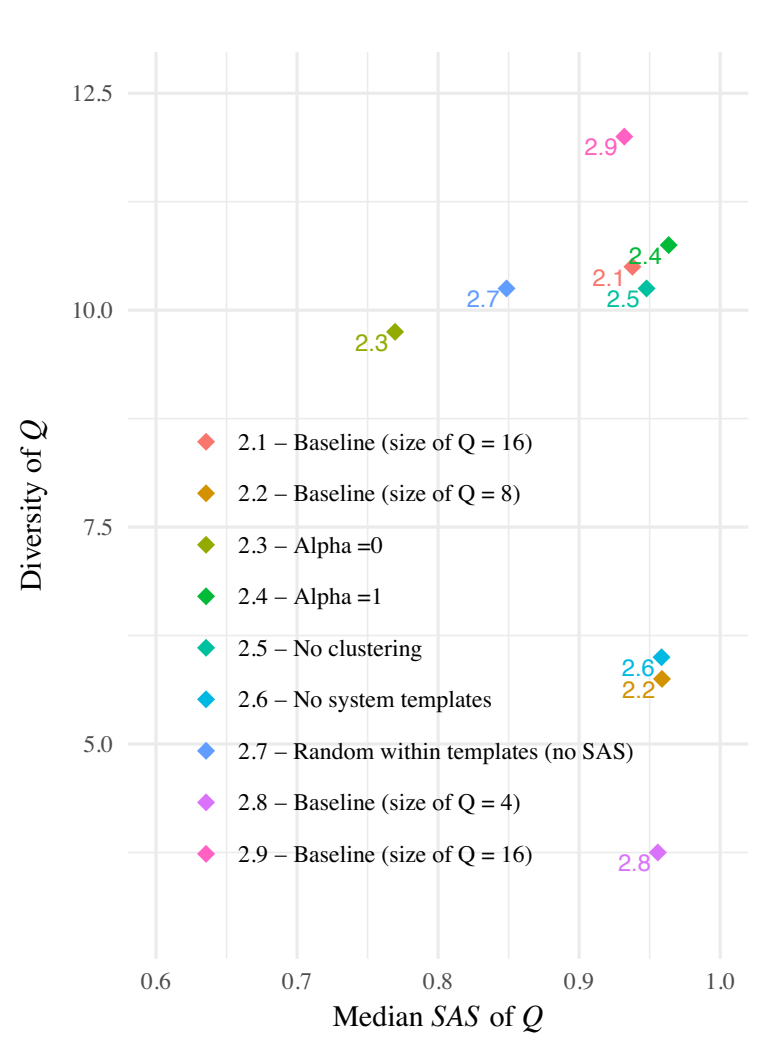

Table 3). The diversity is plotted against the median SanSys appropriateness scores $(S A S)$. Note that runs 2.3 and 2.4 have different $\alpha$, so that their median $S A S$ are not directly comparable.

Figure 12: Characteristics of the set of selected sanitation systems (SanSys) $\boldsymbol{Q}$ for nine different runs for Step 3 (see also 


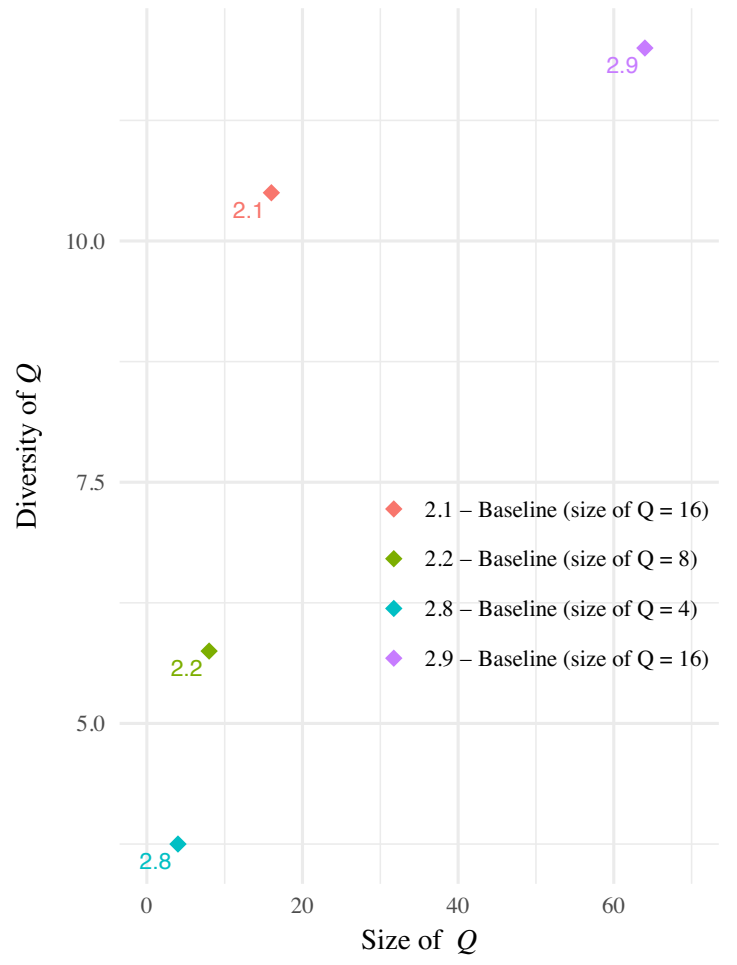

Figure 13: Diversity of the set of selected sanitation systems (SanSys) $\boldsymbol{Q}$ for four different runs (2.1, 2.2, 2.8, and 2.9) as a function of the size of $\boldsymbol{Q}$ (see also

Table 3). The diversity increases with the size of $\boldsymbol{Q}$. The benefit of a large $\boldsymbol{Q}$ for the diversity tempers after the size of $\boldsymbol{Q}$ exceeds the total number of system templates.

\section{Discussion}

The procedure presented here systematizes the generation of a diverse but manageable set of locally appropriate sanitation system options. The core purpose is to break down the typically opaque option generation step into smaller more reproducible elements. It is by no means intended to replace the technical know-how required for detailed planning and implementation but serves to help integrate the growing number of decision criteria and technological options into the decisionmaking process.

In addition, some elements in the procedure still require some degree of judgement. These include (1) the identification of a set of potential technologies; (2) the case-specific choice of the set of screening criteria; (3) the definition of the screening criteria attributes and corresponding uncertainty models; (4) the aggregation method for the TAS and $S A S$ appropriateness scores; (5) the checking of the final set of sanitation system options from a process engineering point of view; and (6) the definition of the system templates and the number of selected options (size of $Q$ ). In the following, we discuss these elements in more detail and argue that, despite these subjectivities and the need for expert judgement, the increased transparency and the formal structure of our approach still offers substantial advance over the currently used approaches.

\subsection{Identification of potential technologies}

The main decisive element of the presented procedure is that it shifts the burden of choosing complete sanitation systems to selecting potential technologies. As this requires no local expertise, we believe that it is easier to compile a comprehensive list of potential technologies (Techs) from literature or experience and then to identify a set of appropriate and complete sanitation systems (SanSys). This is also emphasized by the huge number of potential SanSys, as demonstrated in this paper, compared with the rather limited number of potential Techs. We provide a list of potential Techs based on the literature (Tilley et al. 2014b) and corresponding model input data in the linked dataset for reuse in other applications of the procedures (DOI: 10.5281/zenodo).

\subsection{Choosing a set of screening criteria}

A second decisive element of the procedure is the use of screening criteria to eliminate inappropriate options at the beginning and to streamline the decision-making process. Obviously, which screening criteria are used has an impact on the outcome of the screening procedure. Because no trade-offs are discussed at the screening stage, screening criteria should be exclusively exogenous and as independent of stakeholder preferences as possible. However, in practice the lines are not always clear. Legal directives, cultural constraints, and available skills are often seen as exogenously fixed. However, these might represent current or past stakeholder preferences, such as in the case of legal directives, and can be changed or ignored by the stakeholders. Therefore, the choice of screening criteria relies on the expert in charge of the procedure and will thus imply a certain level of subjectivity about how adaptable they are.

In the example application, we have shown a pathway for structuring the selection of screening criteria as transparently as possible. We provide a carefully assembled master list of possible screening criteria (see Table 1 and SI-A). We then propose involving the stakeholders in selecting case-specific screening criteria.

Because the screening criteria are derived from the overall objective hierarchy of sustainable sanitation, some of them might also be relevant later in the SDM process. For example, a common screening criterion is water use; a potential technology should not exceed the amount of water available in the application case. Nevertheless, the decision-maker still might want to prefer among the appropriate Techs, those with lower water use. 


\subsection{Quantifying attributes and their uncertainty}

A third decisive element of the procedure is the use of attributes for the calculation of appropriateness scores for every technology and sanitation system. Their quantification is based on probability functions characterizing the screening criteria for the technology (Tech attribute) and the application case (AppCase attribute). The selection and quantification of probability function should be mainly data driven and based on data available at the structuring phase of decision making (e.g. household survey, official statistics, baseline reports, former project reports). The uncertainty model for each attribute can then be derived from the data available using the simplest model that describes the data sufficiently (e.g. triangular distribution). The supporting information in SI-A and the data (DOI: 10.5281/zenodo) provide a good starting point for this step.

We are well aware that the detailed choice of attribute and corresponding probability function for each screening criterion might have a substantial impact on the outcome of the analysis (see e.g. section 3.6.1). This step of the procedure depends strongly on the experts in charge of the procedure and therefore also implies a certain level of subjectivity. However, this is a system-immanent problem that many value-focussed SDM procedures face (see e.g. Keeney and Gregory 2005) and not a problem specific to the procedure proposed here.

In the application case, we present a stakeholder-oriented approach, agreeing with them not only about the casespecific screening criteria (see 4.2) but also the attributes by which these are evaluated.

\subsection{Quantifying appropriateness scores TAS and SAS}

A fourth decisive element of the procedure is the technology and system appropriateness scores (TAS and $S A S)$. They express the confidence in how appropriate the technologies and sanitation systems are for a given application case. The appropriateness scores on their own are not sufficiently robust to identify a single most appropriate solution (as shown in the sensitivity analysis in 3.6.1), but they are very well able to show whether any options are significantly more or less promising than others for a specific application case. It therefore acknowledges that hardly any Tech is $100 \%$ appropriate and thus reduces the risk of eliminating options too early. However, it is important to note that the TAS and $S A S$ cannot provide information on the real performance of the technologies and systems in the future. The real performance depends not only on the aspects covered by the screening criteria but also on many other factors such as implementation, influent quality and quantity, and operation and maintenance.

For the quantification of the technology appropriateness score, $T A S$, we aggregate the match of the Tech attribute and the AppCase attribute for all screening criteria. The geometric mean aggregation function satisfies our requirements of allowing different numbers of criteria and turning equal to zero if at least one element is zero (see 2.2.3). However, this aggregation model also implies that the number of criteria used is relevant; the more criteria are used, the less relevance any single criterion has to the overall score. The selection of case-specific criteria from the master list involving stakeholders as described in 4.2 can help to limit the set of screening criteria used to the most relevant. If the list of screening criteria remains long (e.g. greater than 15), we recommend the use of hierarchical structures and of sub-level aggregation, as aggregation via the geometric mean is not an associative function (Grabisch et al. 2011).

To quantify the system appropriateness scores, $S A S$, we propose a weighted multiplicative aggregation model that allows us to define how much long SanSys should be penalized. The main argument here is that the appropriateness of long systems with many technological steps might be judged to be less appropriate than that of shorter and therefore less complex systems with technological elements of same appropriateness. In the application case presented in this paper, we show that the chosen value for $\alpha=0.5$ (see 3.6.2.2) leads to a wellbalanced behaviour that penalizes very long systems but still allows high diversity in the final set of SanSys.

\subsection{Generation of the sanitation system option space}

A fifth decisive element of the procedure is the automatic generation of all possible system combinations. The application example showed that the systematic option generation allows the diversity of the option space to be expanded, as it also results in SanSys options that are not widely applied (see Figure 11c). This enhances the probability that innovative or unusual options find their way into the decision-making. The innovation can lie in how technologies are combined (e.g. combining a urinediverting toilet with vermi-composting) or in the integration of novel technology options. For instance, the model could provide all possible sanitation systems that can be realized with the blue diversion toilet (Larsen et al. 2015). An added benefit of this systematic process is the creation of truly comparable alternatives that incorporate everything from user interface to disposal.

To balance the comprehensiveness of the SanSys option space with the computational efforts required, we used a semi-acyclic algorithm that allows loops only the functional groups storage and treatment $(\mathrm{S})$ and (semi)centralized treatment $(\mathrm{T})$. If there are no computational limitations, the fully cyclic algorithm could be used (see SI-B).

It is important to emphasize that the procedure provides generic SanSys including the technologies and the type of products that flow between them. However, it does not provide (i) detailed characteristics of input or output quantities or qualities or (ii) any spatial information. For example, the semi-centralized composting system 
displayed in Figure 11c could consist either of one central large co-composting site or several smaller ones in different areas of the town.

The SanSys builder is based on a series of simplifications and assumptions. For instance, it requires a standardized set of products and is not able to generate new products, as the model does not have any process engineering knowledge. As a consequence, when different products are mixed together in a conveyance technology, the output product will always be that with the highest degree of pollution. For example, a conventional sewer fed with greywater and blackwater will produce blackwater. The same sewer fed only with blackwater will also produce blackwater. It is clear that the degree of dilution of a certain product might influence the performance of the subsequent treatment step. Another simplification concerns the relationship between the input and output products by 'AND', 'OR', or 'XOR'; this does not allow special cases to be described. For example, a biogas reactor can have dried faeces OR sludge as an input product, but from an engineering perspective dried faeces as the only input does not make too much sense. Therefore, one must assume that some of the permutations might not be sensible from a purely process engineering perspective. This can easily be rectified by checking the set of SanSys selected in step 3 of the procedure before passing them on to the SDM process. Moreover, the SDM process will probably also include a detailed performance evaluation of the SanSys options, where their technical performance can be compared to other decision objectives.

\subsection{Selection of the final set of SanSys options as an input into SDM}

A sixth decision element is the systematic selection of a final set of SanSys. This step is designed to reduce the overwhelming number of SanSys options to a limited number that can be managed by an SDM or MCDA process. The requirements for the algorithm are that (i) the diversity of the set of SanSys is maintained; and (ii) the most appropriate options are selected. The algorithm has four key parameters: (i) the aggregation function used to compute the $S A S$; (ii) the size of the final set of options $Q$; (iii) the system templates (STs); and (iv) the characteristics used for clustering. We showed that the size of $Q$ and the system templates have the highest impact on the diversity of $Q$. The use of the $S A S$ guarantees that only the most appropriate options are selected.

The size of $Q$ depends on the capability of the SDM methodology chosen to treat various numbers of decision options. We show that the diversity increases with the size of $Q$ while the median $S A S$ of $Q$ decreases. The increase in diversity is only relevant until the size of $Q$ exceeds the total number of system templates (see Figure 13). Increasing the size of $Q$ any further then mainly leads to a decrease of the median $S A S$ as an increasing number of less appropriate SanSys are included in $Q$. This shows that there exists a quasi-optimal size of $Q$ even if the
SDM methodology were able to manage very high number of options. This optimal size is equal to or slightly higher than the number of defined system templates.

The way system templates are defined also influences how much weight different groups of system templates might gain in $Q$. In the example application, we decomposed the group of blackwater system templates into seven subtemplates (see Table 5), compared to only two subtemplates for the onsite simple, thus giving blackwater systems a higher weight. We argue that the number of Techs available is higher in the blackwater group and that the diversity of these options should be accounted for. However, other definitions might be more suitable for other decision contexts. There is some subjectivity in how the system templates are defined; however, this is also the case for the diversity of decision options that may be requested (Gregory et al. 2012, Keeney 1996). We here suggest verifying the choice of system templates with the stakeholders in an application case.

\subsection{Limitations and outlook}

The main limitations of the procedure presented here lie in the experts' skills and local knowledge to provide suitable inputs. In the future, this procedure could therefore be more strongly adapted to different settings so as to connect it more intimately with existing planning procedures. Good results might be achieved by using the proposed procedure to generate technology profiles and system option compendiums. Specialized knowledge and available sanitation-relevant data could be used to characterize the technology profiles. The SanSys builder could be used to generate the corresponding system compendium. These products could then be used in local sanitation planning processes to identify appropriate technology profiles and system options as input for local decision-making (e.g. CLUES). This would allow a standardized approach that combines in-depth expert knowledge about potential technologies with local data and preferences. The appropriateness assessment based on the technology profiles can be discretized, which would make it independent of modelling software. As much of the system generation and option selection procedures are algorithms, the system compendium could be implemented as a web-based service that centralizes in-depth technical know-how and provides the user with localized options. In addition, specific technology profiles and system compendiums could be generated for typical regions and settings. The system templates could be defined in a way to correlate with appropriateness ranges for different regions, which would further facilitate the integration of the approach into the local sanitation planning process.

An interesting extension of the SanSys builder would be the addition of a material flow analysis module. This would allow for the quantitative estimation of the performance of entire sanitation systems including nutrient, water, or solids recovery potentials as additional 
indicators that can be used by the decision-making process.

\section{Conclusions}

We present a codified and therefore reproducible procedure to identify an initial set of SanSys decision options as an input into a structured decision making (SDM) process such as CLUES, a strategic sanitation planning guideline developed for urban settings in the global South (Lüthi et al. 2011). The procedure is not meant to identify the best option, because this is what SDM does. Instead, it focusses on potentially appropriate options while maintaining high conceptual diversity. Furthermore, it is meant not to replace but to support engineering know-how in an SDM process. It provides a series of advantages over currently used empirical methods:

i. It is automated and thus allows very large numbers of technology and system options to be dealt with;

ii. It makes technical suggestions for each and every product and therefore enforces the consideration of entire sanitation systems;

iii. it is systematic and thus enhances the reproducibility and transparency of option generation;

iv. it explicitly considers uncertainties relating to local conditions and technology options and thus can work with data and information generally available at the structuring phase, also in developing urban areas; and

v. it can include novel technologies and therefore generates options that have not yet been widely applied but are nevertheless realistic (as shown in the application case). The hope is that such novel options have the potential to be more sustainable than conventional ones in developing urban areas because of e.g. their greater flexibility to

\section{References}

Amoah, P., Nartey, E.G. and Schrecongost, A. (2016) Performance evaluation of biofil toilet waste digester technologies in Ghana: the efficacy of effluent treatment options. Environmental Technology (United Kingdom), 1-12.

Ashley, R., Blackwood, D., Butler, D., Jowitt, P., Davies, J., Smith, H., Gilmour, D. and Oltean-Dumbrava, C. (2008) Making asset investment decisions for wastewater systems that include sustainability. Journal of Environmental Engineering 134(3), 200-209.

Balkema, A.J., Preisig, H.A., Otterpohl, R. and Lambert, F.J. (2002) Indicators for the sustainability assessment of wastewater treatment systems. Urban water 4(2), 153-161.

Barnes, R. and Ashbolt, N. (2006) Review of Decision Tools and Trends for Water and Sanitation Development Projects, demographic changes and the opportunities for resource recovery (e.g. nutrients, energy, or water). The procedure remains sensitive to several parameters that should ideally be defined together with local stakeholders: the definition of potential technologies; the set of screening criteria, attributes, and uncertainty models; and the system templates. Moreover, the procedure is generic and can be extended to integrate other parts of urban water systems (e.g. stormwater) and applied to other complex infrastructure problems, such as solid waste management. The procedure is sufficiently systematic that it could be standardized for regional or national planning procedures and provide low-level support for local decision-making and planning procedures.

\section{Acknowledgments:}

The authors gratefully acknowledge Mingma and Anjali Sherpa and Bipin Dangol for providing inputs on the practical application of the method. The inputs from Fridolin Haag, Dr. Mika Marttunen and Dr. Christoph Lüthi helped us to define decision objectives and to develop a method for identifying screening criteria. Judith Lienert's inputs on SDM helped us to improve the methodological approach. The authors also thank Joel Gundlach and Maria Rath for reviewing and testing the models. Furthermore, the authors gratefully thank Agnes Montangero and her colleagues from the Swiss Water and Sanitation Consortium and the inhabitants of Katarniya for providing their project as an application case.

This work was supported by the Engineering for Development (E4D) programme of the Swiss Federal Institute for Technology (ETH) Zurich. The programme is funded through the Sawiris Foundation for Social Development.

Sanitation, Water, Engineering and Development Centre (WEDC), Colombo.

Bezanson, J., Edelman, A., Karpinski, S. and Shah, V.B. (2017) Julia: A Fresh Approach to Numerical Computing. SIAM Review 59(1), 65-98.

Bouabid, A. and Louis, G.E. (2015) Capacity factor analysis for evaluating water and sanitation infrastructure choices for developing communities. Journal of Environmental Management 161, 335-343.

Bracken, P., Kvarnström, E., Ysunza, A., Kärrman, E., Finnson, A. and Saywell, D. (2005) Making sustainable choices-the development and use of sustainability oriented criteria in sanitary decision making, pp. 23-26.

Chen, J. and Beck, M. (1997) Towards designing sustainable urban wastewater infrastructures: a screening analysis. Water Science and Technology 35(9), 99-112. 
Chen, Y., Kilgour, D.M. and Hipel, K.W. (2008) Screening in multiple criteria decision analysis. Decision Support Systems 45(2), 278-290.

Dalecha, T., Assefa, E., Krasteva, K., Langergraber, G (2012) Experiments on struvite precipitation, application and economic analysis in Arba Minch, Ethopia, Durban, South Africa.

Dodman, D., Dalal-Clayton, B. and McGranahan, G. (2013) Integrating the environment in urban planning and management - Key principles and approaches for cities in the 21st century, United Nations Environment Programme (UNEP).

Dunmade, I. (2002) Indicators of sustainability: assessing the suitability of a foreign technology for a developing economy. Technology in Society 24(4), 461-471.

Eisenführ, F., Weber, M. and Langer, T. (2010) Rational decision making, Springer.

Goldhoff, R.M. (1976) Appropriate technology: an approach to satisfying the technical needs of developing countries. American Society of Mechanical Engineers (Paper) (76 WA/TS-12).

Grabisch, M., Marichal, J.-L., Mesiar, R. and Pap, E. (2011) Aggregation functions: Means. Information Sciences 181(1), $1-22$.

Gregory, R., Failing, L., Harstone, M., Long, G., McDaniels, T. and Ohlson, D. (2012) Structured decision making: a practical guide to environmental management choices, John Wiley \& Sons.

Hajkowicz, S. and Collins, K. (2007) A review of multiple criteria analysis for water resource planning and management. Water Resources Management 21(9), 1553-1566.

Hastie, T., Tibshirani, R. and Friedman, J.H. (2009) The elements of statistical learning: data mining, inference, and prediction, Springer, New York.

Hendriksen, A., Tukahirwa, J., Oosterveer, P.J. and Mol, A.P. (2012) Participatory decision making for sanitation improvements in unplanned urban settlements in East Africa. The Journal of Environment \& Development 21(1), 98-119.

Hoffmann, B., Nielsen, S.B., Elle, M., Gabriel, S., Eilersen, A.M., Henze, M. and Mikkelsen, P.S. (2000) Assessing the sustainability of small wastewater systems A context-oriented planning approach. Environmental Impact Assessment Review 20(3), 347-357.

Isunju, J.B., Schwartz, K., Schouten, M.A., Johnson, W.P. and van Dijk, M.P. (2011) Socio-economic aspects of improved sanitation in slums: a review. Public Health 125(6), 368-376.

Iwugo, K.O. (1979) Appropriate sanitation technology planning and implementation in Africa. Environmental Pollution Management 9(4), 100-102.
Kalbermatten, J.M., Julius, D.S., Gunnerson, C.G. and Mundial, B. (1980) Appropriate technology for water supply and sanitation; a summary of technical and economic options, World Bank, Washington.

Keeney, R.L. (1996) Value-focused thinking: Identifying decision opportunities and creating alternatives. European Journal of Operational Research 92(3), 537-549.

Keeney, R.L. (2002) Common mistakes in making value trade-offs. Operations Research 50(6), 935-945+1077.

Keeney, R.L. and Gregory, R.S. (2005) Selecting attributes to measure the achievement of objectives. Operations Research 53(1), 1-11.

Kilgour, D.M., Rajabi, S., Hipel, K.W. and Chen, Y.E. (2004) Screening alternatives in multiple criteria subset selection. INFOR 42(1), 43-60.

Krebs, P. and Larsen, T.A. (1997) Guiding the development of urban drainage systems by sustainability criteria. Water Science and Technology 35(9), 89-98.

Kvarnström, E., Bracken, P., Ysunza, A., Kärrman, E., Finnson, A. and Saywell, D. (2004) Sustainability criteria in sanitation planning, pp. 104-107.

Kvarnström, E., McConville, J., Bracken, P., Johansson, M. and Fogde, M. (2011) The sanitation ladder - a need for a revamp? Journal of Water, Sanitation and Hygiene For Development 1(1), 3 .

Kvarnström, E. and Petersens, E.a. (2004) Open planning of sanitation systems, EcoSanRes Programme.

Lalander, C.H., Hill, G.B. and Vinnerås, B. (2013) Hygienic quality of faeces treated in urine diverting vermicomposting toilets. Waste Manag 33(11), 2204-2210.

Langhans, S.D., Reichert, P. and Schuwirth, N. (2014) The method matters: A guide for indicator aggregation in ecological assessments. Ecological Indicators 45, 494-507.

Larsen, T. and Gujer, W. (1997) The concept of sustainable urban water management. Water Science and Technology 35(9), 3-10.

Larsen, T.A., Gebauer, H., Gründl, H., Künzle, R., Lüthi, C., Messmer, U., Morgenroth, E., Niwagaba, C.B. and Ranner, B. (2015) Blue Diversion: a new approach to sanitation in informal settlements. Journal of Water Sanitation and Hygiene for Development 5(1), 64-71.

Larsen, T.A., Hoffmann, S., Lüthi, C., Truffer, B. and Maurer, M. (2016) Emerging solutions to the water challenges of an urbanizing world. Science 352(6288), 928-933.

Larsen, T.A., Maurer, M., Eggen, R.I., Pronk, W. and Lienert, J. (2010) Decision support in urban water management based on generic scenarios: the example of NoMix technology. Journal of Environmental Management 91(12), 2676-2687. 
Lennartsson, M., Kvarnström, E., Lundberg, T., Buenfil, J. and Sawyer, R. (2009) Comparing sanitation systems using sustainability criteria, EcoSanRes Programme.

Loetscher, T. (1999) Appropriate sanitation in developing countries: the development of a computerised decision aid.

Lundie, S., Peters, G.M., Ashbolt, N., Lai, E. and Livingston, D. (2006) A sustainability framework for the Australian water industry. Jounral of the Australian Water Association November, 83-88.

Lundin, M., Molander, S. and Morrison, G. (1999) A set of indicators for the assessment of temporal variations in the sustainability of sanitary systems. Water Science and Technology 39(5), 235-242.

Lüthi, C., Morel, A., Tilley, E. and Ulrich, L. (2011) Community-Led Urban Environmental Sanitation Planning (CLUES), Swiss Federal Institute of Aquatic Science and Technology (Eawag), Dubendorf.

Lüthi, C. and Parkinson, J. (2011) Environmental sanitation planning for cities of the South: linking local level initiatives with city-wide action, Loughborough, UK.

Magara, Y., Kunikane, S. and Aoyama, S. (1986) Factors influencing the selection of appropriate sanitation technology. Water Science and Technology 18(7-8), 129-136.

Marttunen, M., Lienert, J. and Belton, V. (2017) Structuring problems for Multi-Criteria Decision Analysis in practice: A literature review of method combinations. European Journal of Operational Research 263(1), 1-17.

Maurer, M., Bufardi, A., Tilley, E., Zurbrügg, C. and Truffer, B. (2012) A compatibility-based procedure designed to generate potential sanitation system alternatives. Journal of Environmental Management 104(15 August, 2012), 51-61.

McConville, J. (2010) Unpacking Sanitation Planning. Comparing Theory and Practice, Chalmers University of Technology, Gothenburg, Sweden.

McConville, J.R., Künzle, R., Messmer, U., Udert, K.M. and Larsen, T.A. (2014) Decision support for redesigning wastewater treatment technologies. Environmental Science and Technology 48(20), 12238-12246.

Menck, K.W. (1973) The concept of appropriate technology. Intereconomics 8(1), 8-10.

Motevallian, S. and Tabesh, M. (2011) A Framework for Sustainability Assessment of Urban Water Systems Using a Participatory Approach.

Munamati, M., Nhapi, I. and Misi, S.N. (2017) Types and distribution of improved sanitation technologies in subSaharan Africa. Journal of Water Sanitation and Hygiene for Development 7(2), 260-271.

Nayono, S. (2014) Development of a Sustainability-based Sanitation Planning Tool (SusTA) for Developing Countries, Weimar.
Palme, U., Lundin, M., Tillman, A.-M. and Molander, S. (2005) Sustainable development indicators for wastewater systems - researchers and indicator users in a co-operative case study. Resources, Conservation and Recycling 43(3), 293-311.

Parker, A. (2014) Membrane technology plays key role in waterless hygienic toilet. Membrane Technology 2014(12), 8.

Parkinson, J., Lüthi, C. and Walther, D. (2014) Sanitation 21. A Planning Framework for Improving City-wide Sanitation Service, International Water Association (IWA), London.

Pollesch, N. and Dale, V.H. (2015) Applications of aggregation theory to sustainability assessment. Ecological Economics 114, 117-127.

R Development Core Team (2015) R: A language and environment for statistical computing, R Foundation for Statistical Computing, Vienna, Austria.

Ramôa, A., Lüthi, C., McConville, J. and Matos, J. (2016) Urban sanitation technology decision-making in developing countries: a critical analysis of process guides. International Journal of Urban Sustainable Development 8(2), 191-209.

Ramôa, A.R., McConville, J., Lüthi, C. and Matos, J.S. (2018) Use of process guides for comprehensive urban sanitation technology decision-making: practice versus theory. Water policy 20(1), 158-174.

Rowley, H.V., Peters, G.M., Lundie, S. and Moore, S.J. (2012) Aggregating sustainability indicators: Beyond the weighted sum. Journal of Environmental Management 111(0), 24-33.

Sahely, H.R., Kennedy, C.A. and Adams, B.J. (2005) Developing sustainability criteria for urban infrastructure systems. Canadian Journal of Civil Engineering 32(1), 72-85.

Schumacher, E.F. (1973) Small is beautiful: a study of economics as if people really mattered, Vintage, London.

Schuwirth, N., Reichert, P. and Lienert, J. (2012)

Methodological aspects of multi-criteria decision analysis for policy support: A case study on pharmaceutical removal from hospital wastewater. European Journal of Operational Research 220(2), 472-483.

Sherpa, M.G., Lüthi, C. and Koottatep, T. (2012) Applying the household-centered environmental sanitation planning approach: A case study from Nepal. Journal of Water Sanitation and Hygiene for Development 2(2), 124-132.

Singhirunnusorn, W. and Stenstrom, M. (2009) Appropriate wastewater treatment systems for developing countries: criteria and indicator assessment in Thailand. Water Science and Technology 59(9), 1873-.

Starkl, M., Brunner, N. and Stenström, T.-A. (2013) Why Do Water and Sanitation Systems for the Poor Still Fail? Policy Analysis in Economically Advanced Developing Countries. Environmental Science \& Technology 47(12), 6102-6110. 
Strande, L. (2014) Faecal waste: the next sanitaiton challenge. Water 21 June 2014

SuSanA (2008) Towards more sustainable sanitation solutions - SuSanA Vision document, Sustainable Sanitation alliance (SuSanA).

Tilley, E., Strande, L., Lüthi, C., Mosler, H.-J., Udert, K.M., Gebauer, H. and Hering, J.G. (2014a) Looking beyond Technology: An Integrated Approach to Water, Sanitation and Hygiene in Low Income Countries. Environmental Science \& Technology.

Tilley, E., Ulrich, L., Lüthi, C., Reymond, P. and Zurbrügg, C. (2014b) Compendium of Sanitation Systems and Technologies - 2nd revised edition, Swiss Federal Institute of Aquatic Science and Technology (EAWAG), Duebendorf, Switzerland.

Tilley, E., Zurbrügg, C. and Lüthi, C. (2010) Social Perspectives on the Sanitation Challenge, pp. 69-86.

Tilmans, S., Russel, K., Sklar, R., Page, L., Kramer, S. and Davis, J. (2015) Container-based sanitation: assessing costs and effectiveness of excreta management in Cap Haitien, Haiti. Environment and Urbanization 27(1), 89-104.

Tobias, R., O'Keefe, M., Künzle, R., Gebauer, H., Gründl, H., Morgenroth, E., Pronk, W. and Larsen, T.A. (2017) Early testing of new sanitation technology for urban slums: The case of the Blue Diversion Toilet. Science of the total environment $576,264-272$.

Tremolet, S., Kolsky, P. and Perez, E. (2010) Financing OnSite Sanitation for the Poor. A Six Country Comparative Review and Analysis.

UN (2000) Millennium Development Goals, United Nations.
UN (2015) Transforming our world: the 2030 Agenda for Sustainable Development, United Nations (UN), New York.

UNFPA (2007) State of world population 2007: unleashing the potential of urban growth. Martine, G. and Marshall, A. (eds), United Nations Population Fund (UNFPA).

UNW-DPC (2013) Safe Use of Wastewater in Agriculture. Liebe, J. and Ardakanian, R. (eds), UN-Water Decade Programme on Capacity Development (UNW-DPC), Bonn, Germenay.

van Buuren, J. and Hendriksen, A. (2010) Social Perspectives on the Sanitation Challenge. van Vliet, B., Spaargaren, G. and Oosterveer, P. (eds), pp. 87-103, Springer Netherlands, Dordrecht.

WHO (2013) World health report 2013: Research for universal health coverage, World Health Organization (WHO), Geneva, Switzerland.

WHO and UNICEF (2017) Progress on Drinking Water, Sanitation and Hygiene, Geneva, Switzerland.

Willetts, J., Willetts, M., Paddon, N.D.G., Nam, N., Trung, N. and Carrard (2013) Sustainability assessment of sanitation options in Vietnam: planning with the future in mind. Journal of Water, Sanitation and Hygiene For Development 3(2), 262.

WSP (2014) The Missing Link in Sanitation Service Delivery. A Review of Fecal Sludge Management in 12 Cities, International Bank for Reconstruction and Development/The World Bank.

Zurbrügg, C., Bufardi, A., Tilley, E., Maurer, M. and Truffer, B. (2009) Decision-making for sanitation systems. Sandec News 10, 20-21. 